\title{
A potential use for the C-band polarimetric SAR parameters to characterise the soil surface over bare agriculture fields
}

\author{
Nicolas Baghdadi, Remi Cresson, Eric Pottier, Maelle Aubert, Zribi Mehrez, Andres Jacome, and \\ Sihem Benabdallah
}

\begin{abstract}
The objective of this study was to analyze the potential of the C-band polarimetric SAR parameters for the soil surface characterization of bare agricultural soils. RADARSAT-2 data and simulations using the Integral Equation Model (IEM) were analyzed to evaluate the polarimetric SAR parameters' sensitivities to the soil moisture and surface roughness.

The results showed that the polarimetric parameters in the $\mathbf{C}$ band were not very relevant to the characterization of the soil surface over bare agricultural areas. Low dynamics were often observed between the polarimetric parameters and both the soil moisture content and the soil surface roughness. These low dynamics do not allow for the accurate estimation of the soil parameters, but they could augment the standard inversion approaches to improve the estimation of these soil parameters. The polarimetric parameter $\alpha_{1}$ could be used to detect very moist soils $(>30 \%)$, while the anisotropy could be used to separate the smooth soils.
\end{abstract}

Index Terms - Polarimetric SAR data, RADARSAT-2, soil surface characteristics, bare agricultural soils.

\section{INTRODUCTION}

Q oil surface characteristics, namely the soil moisture content $\checkmark$ and roughness, play an important role in different applications such as hydrology, agronomy or meteorology. Floods, excess runoff, and soil erosion are, among others, key factors controlled and influenced by soil surface conditions [1]-[3]. Indeed, soil moisture and surface roughness affect

Manuscript received xxx. This work was supported in part by $\mathrm{xxx}$

N. Baghdadi is with IRSTEA, UMR TETIS, 500 rue François Breton, 34093 Montpellier cedex 5, France, E-mail: nicolas.baghdadi@ teledetection.fr, phone: 334675487 24; Fax: 3346754 8700

R. Cresson is with IRSTEA, UMR TETIS, 500 rue François Breton, 34093 Montpellier cedex 5, France

E. Pottier is with the University of Rennes 1, IETR, 35042 Rennes Cedex, France

M. Aubert is with IRSTEA, UMR TETIS, 500 rue François Breton, 34093 Montpellier cedex 5, France

M. Zribi is with the IRD-CESBIO, 18 av. Edouard Belin, BP 2801, 31401 Toulouse cedex 9, France

A. Jacome is with the INRS-Ete, 490 rue de la Couronne, Québec G1K9A9, Canada

S. Benabdallah is with the Centre de Recherches et Technologies des Eaux, Ecoparc Borj Cédria. BP 273, Soliman 8020, Tunisie numerous processes on the soil surface such as infiltration capacity, temporary surface storage, deposition or detachment of particles, etc. Numerous research studies that have been performed during the three last decades have shown that Synthetic Aperture Radar (SAR) sensors have a high potential to measure the surface soil moisture [4]-[9]. It is well known that the SAR return signal over bare soil surfaces is affected by surface characteristics such as the soil's roughness and dielectric constant. The amount of soil moisture influences the return signal depending on the dielectric properties of the soil. The soil roughness determines the type of radiation that is reflected. A very smooth surface reflects all of the energy in the specular direction and no signals reach the antenna, whereas a very rough surface diffuses the incident wave in all directions [10]. Moreover, the radar signal depends on the radar parameters such as polarisation, incidence angle and radar wavelength [10], [11].

The primary surface soil moisture retrieving approaches use SAR data in the C-band because of the high availability of spatial SAR images in this radar band frequency (ERS-1/2, RADARSAT-1/2 and ASAR). Several studies have shown that the best estimates of soil moisture over bare soil surfaces are obtained with SAR images that are acquired at both low and high incidence angles or by using polarimetric SAR data [6], [9], [12]-[14]. Currently, satellite SAR data are acquired with one incidence angle and one radar wavelength. Moreover, except for RADARSAT-2 which is polarimetric sensor, the current satellite SARs allow acquisitions only with one or two polarizations. Because the radar signal is strongly influenced by both soil moisture and surface roughness the inversion problem is difficult to solve based on the multitude of solutions that exist for the surface roughness and the soil moisture. By using two incidence angles (for example, $20^{\circ}$ and $\left.40^{\circ}\right)$, it is possible to eliminate the effects of roughness and therefore to link the radar backscattering coefficients to the moisture only. The most common approaches that are used to determine the surface soil parameters from polarimetric SAR data are those that were proposed by [12]-13]; these approaches uses an inversion diagram that is based on either the cross-polarized backscattering coefficient $\sigma^{\circ}{ }_{\mathrm{HV}}$ and the copolarized ratio $\left(\sigma_{\mathrm{HH}}^{\circ} / \sigma_{\mathrm{VV}}^{\circ}\right)$ or the co-polarized ratio $\left(\sigma^{\circ}{ }_{\mathrm{HH}} / \sigma^{\circ}{ }_{\mathrm{VV}}\right)$ and the cross-polarized ratio $\left(\sigma^{\circ}{ }_{\mathrm{VH}} / \sigma^{\circ} \mathrm{VV}\right)$. [6] 
showed that the accuracy of the soil moisture estimate does not improve significantly $(<1 \%)$ when two polarisations ( $\mathrm{HH}$ and HV, C-band) are used instead of only one polarisation. To obtain an estimate of soil moisture when using SAR observations that only use one channel, it is necessary to use radar configurations that minimise the effects of the other soil surface characteristics, such as surface roughness [6], [15]. The optimal radar incidences in the C-band for the retrieval of soil moisture are between $10^{\circ}$ and $20^{\circ}$ [16]-[17], whereas those for the estimation of surface roughness are greater than $40^{\circ}[15]$.

There is currently a great challenge to demonstrate an interest in the use of polarimetric parameters in order to estimate surface roughness and soil moisture. Only a few studies have analysed the potential uses of polarimetric SAR data for the estimation of surface roughness and soil moisture over bare agricultural fields [18]-[21]. [21] proposed a model for the inversion of soil parameters based on the eigenvalues and eigenvectors of the polarimetric coherency matrix. The inversion of the fully polarimetric airborne L-band SAR data were investigated by using three polarimetric parameters, namely the scattering entropy, the scattering anisotropy, and the alpha angle. The model is an extension of the small perturbation model (SPM) and assumes the reflection of symmetric surfaces. The SPM model is valid for soils in which the surface heights are small compared to the radar wavelength $(k s<0.3$, where $k$ is the radar wave number and $s$ is the root mean square ( $\mathrm{rms}$ ) surface height of soil surface roughness). The typical $s$-values of the agricultural bare soils range from 0.5 to $4 \mathrm{~cm}$ [22]-[23], and at the L-band $(\sim 1.25 \mathrm{GHz}$; $\left.k=0.24 \mathrm{~cm}^{-1}\right)$, the $s$-values $(0.12<k s<0.96)$ largely exceed the SPM validity region. The model of Hajnsek et al. [21] estimated the $k s$ directly from the anisotropy values and the dielectric constant from the diagram of entropy/alpha angle. This approach is not applicable to the C-band $(\sim 5.3 \mathrm{GHz}$; $\left.k=1.11 \mathrm{~cm}^{-1}\right)$ because the $k s$ values $(0.55<k s<4.44)$ would be well beyond the validity domain of the SPM model. [19] proposed inversion algorithms using either mono- or multifrequency polarimetric data. Their approach introduced a polarimetric scattering model that was based on the Integral Equation Model (IEM; [11]) and the use of the entropy (H), the $\alpha_{1}$ angle and a new polarimetric parameter, which was named the eigenvalue relative difference (ERD). For the mono-frequency data, the most adapted radar wavelength $(\lambda)$ for the soil parameters estimation is the L-band ( $\lambda$ between 15 and $30 \mathrm{~cm}$ ) due to its sensitivity to both soil moisture and surface roughness. In the multi-frequency inversion algorithm, the soil moisture is estimated from $\alpha_{1}$, which is acquired in the high frequency band ( $\mathrm{C}$ to $\mathrm{K}$ band: 4 to $27 \mathrm{GHz}$ ) whereas the rms surface height is obtained from the parameters $\alpha_{1}, \mathrm{H}$ and ERD in the low frequency band (P to $\mathrm{S}$ band: 0.3 to $4 \mathrm{GHz}$ ).

The objective of the present study is to investigate the sensitivity of polarimetric parameters at the C-band to bare agricultural soil parameters (soil moisture and surface roughness). Indeed, the potential of polarimetric parameters in the C-band was studied little and the available SAR studies use especially high radar wavelengths as the L-band. The main investigation in this study concerns the analysis of the dynamic of polarimetric parameters in the C-band according to soil moisture and surface roughness. Twelve RADARSAT-2 images in the polarimetric mode were analysed and compared to IEM simulations. This work will enable us to evaluate the potential of polarimetric SAR sensors at the C-band to extract surface soil parameters for two study sites in France. Section 2 provides a review of the IEM model and the main polarimetric parameters. In Section 3, the data set is described. The results are shown in Section 4, and finally, Section 5 presents the main conclusions.

\section{POLARIMETRIC SCATTERING MODE}

\section{A. Polarimetric parameters}

A polarimetric Synthetic Aperture Radar (SAR) measures the scattering matrix $S$ of a medium with quad polarisations. This matrix is constituted by the complex scattering coefficients $S_{p \mathrm{q}}$, where $\mathrm{p}$ is the transmitting polarisation and $\mathrm{q}$ is the receiving polarisation ( $\mathrm{p}, \mathrm{q}=\mathrm{H}$ or $\mathrm{V}$, where $\mathrm{H}$ represents horizontal and $\mathrm{V}$ represents vertical). The polarimetric information in the monostatic case can be represented by a coherency matrix $T$ which can be calculated from the complex target vector $k_{p}$ as follows [24]:

$$
\begin{aligned}
& T=\left\langle k_{p} \cdot k_{p}^{* T}\right\rangle \text { with } \\
& k_{p}=\frac{1}{\sqrt{2}}\left(S_{h h}+S_{v v} \quad S_{h h}-S_{v v} \quad 2 S_{h v}\right)^{T}
\end{aligned}
$$

where the superscripts ${ }^{*},{ }^{\mathrm{T}}$ and <.> denote the complex conjugate, the matrix transpose, and the average operator, respectively.

[24] proposed a polarimetric decomposition theorem that is based on the eigenvector/value of the coherency matrix into elementary mechanisms (i.e. single, double and volume scattering) to identify the global mean scattering mechanism. The matrix $T$ can be defined as the noncoherent sum of three orthogonal unitary matrices as follows:

$$
T=\sum_{i=1}^{3} \lambda_{i} V_{i} V_{i}^{* T}
$$

where $\lambda_{i}$ are the three eigenvalues of $T$, which are real and non-negative $\lambda_{1} \geq \lambda_{2} \geq \lambda_{3} \geq 0 . V_{i}$ are the related orthogonal unitary eigenvectors.

Using the eigenvectors and eigenvalues, three main parameters are used to characterise the results of this decomposition: entropy $(H)$, mean alpha angle $(\bar{\alpha})$, and anisotropy $(A)$. The polarimetric scattering entropy $H$ is 
defined from the logarithmic sum of the eigenvalues of $T$ and represents the random behaviour of the scattering phenomenon as follows:

$$
H=-\sum_{i=1}^{3} P_{i} \cdot \log _{3}\left(P_{i}\right) \quad, \quad 0 \leq H \leq 1
$$

where $P_{i}$ are the normalised eigenvalues as follows:

$$
P_{i}=\frac{\lambda_{i}}{\sum_{j=1}^{3} \lambda_{j}}
$$

The entropy $H$ is a measure of the randomness of the scattering mechanisms. Low entropy $(H \sim 0)$ indicates a single scattering mechanism (isotropic scattering) while high entropy $(H \sim 1)$ indicates a totally random mixture of scattering mechanisms with equal probability and, therefore, a depolarising target.

The mean scattering angle $\bar{\alpha}$ represents the mean dominant scattering mechanism and it is calculated from the eigenvectors and eigenvalues of $T$ :

$$
\bar{\alpha}=\sum_{i=1}^{3} \alpha_{i} P_{i}
$$

where $\alpha_{i}$ are the scattering mechanisms that are represented by the three eigenvectors. $\bar{\alpha}=0^{\circ}$ indicates a surface scattering, $\bar{\alpha}=45^{\circ}$ indicates a dipole mechanism (volume scattering), and $\bar{\alpha}=90^{\circ}$ indicates a double bounce scattering from metallic surfaces (dihedral scatter).

The anisotropy $A$ is defined as the relative importance of the secondary scattering mechanism and it is expressed as:

$$
A=\frac{\lambda_{2}-\lambda_{3}}{\lambda_{2}+\lambda_{3}} \quad, \quad 0 \leq A \leq 1
$$

where $\lambda_{2}$ and $\lambda_{3}$ are the two lowest eigenvalues. $A$ becomes 0 if both of the scattering mechanisms are of equal proportion, while the larger values of A indicates the increasing amounts of anisotropic scattering.

The reflection symmetry hypothesis, which is valid for agricultural surfaces, allows the derivation from the coherency matrix $T$ of the analytical expressions of the polarimetric parameters. In this case, the correlation between the co- and cross-polarized channels is assumed to be zero $\left(\left\langle S_{H H} S_{H V}{ }^{*}\right\rangle=\right.$ $\left.\left\langle S_{V V} S_{H V} *\right\rangle=0\right)$ [25]. The simplified expressions of the NonOrdered in Size (NOS) eigenvalues are defined as follows [26]:

$$
\begin{aligned}
& \left.\lambda_{1 \text { NOS }}=\frac{1}{2}\left(\left\langle\left|S_{h h}\right|^{2}\right\rangle+\left\langle\left|S_{w v}\right|^{2}\right\rangle+\sqrt{\left(\left\langle\left|S_{h h}\right|^{2}\right\rangle-\left\langle\left|S_{w v}\right|^{2}\right\rangle\right)^{2}+4<\left|S_{h h} S_{w v}\right|^{2}}\right\rangle\right) \\
& \left.\lambda_{2 \text { NOS }}=\frac{1}{2}\left(\left\langle\left|S_{h h}\right|^{2}\right\rangle+<\left|S_{w v}\right|^{2}\right\rangle-\sqrt{\left.\left.\left(\left\langle\left|S_{h h}\right|^{2}\right\rangle-<\left|S_{w}\right|^{2}\right\rangle\right)^{2}+4<\left|S_{h h} S_{w v}\right|^{2}\right\rangle}\right) \\
& \lambda_{3 \text { NOS }}=2\left\langle\left|S_{h v}\right|^{2}\right\rangle
\end{aligned}
$$

The eigenvectors can also be written analytically in the case of reflection symmetry hypothesis [26].

[18] suggest the analysis of the alpha angle that corresponds to the first eigenvector $\left(\alpha_{1}\right)$ rather than the mean scattering alpha $(\bar{\alpha})$ because $\alpha_{1}$ indicates the type of the scattering process that is associated with the first eigenvector and then with the dominating scattering process. A value of $\alpha_{1}$ that is lower than $45^{\circ}$ corresponds to surface scattering. The $\alpha_{1}$ parameter is given by the following:

$\alpha_{1}=\arctan \left(\frac{\sqrt{\left|v_{1}(2)\right|^{2}+\left|v_{1}(3)\right|^{2}}}{\left|v_{1}(1)\right|^{2}}\right)$

Where $v_{I}(i)$ is the $i$ th component of the first eigenvector $v_{I}$ and || is the module.

Moreover, [20] introduced two new parameters, which are called the Single-bounce Eigenvalue Relative Difference (SERD) and the Double-bounce Eigenvalue Relative Difference (DERD), to provide a better inversion of the geophysical parameters in the natural media:

$S E R D=\frac{\lambda_{S}-\lambda_{3 N O S}}{\lambda_{S}+\lambda_{3 N O S}} \& D E R D=\frac{\lambda_{D}-\lambda_{3 N O S}}{\lambda_{D}+\lambda_{3 N O S}}$

$\lambda_{\mathrm{S}}$ is associated to the single reflection mechanism and $\lambda_{\mathrm{D}}$ is associated to the double reflection. For $\alpha_{1}<\pi / 4, \alpha_{2}$ is higher than $\pi / 4$, then $\lambda_{S}=\lambda_{1 N O S}$ and $\lambda_{D}=\lambda_{2 N O S}$. If $\alpha_{1}>\pi / 4 \rightarrow \alpha_{2}<\pi / 4$ then $\lambda_{S}=\lambda_{2 \mathrm{NOS}}$ and $\lambda_{\mathrm{D}}=\lambda_{1 \mathrm{NOS}}$.

In this study, only the following polarimetric descriptors that were considered to be important for the characterisation of the soil surface parameters were analysed: the angle $\alpha_{1}$, the entropy $(H)$, the anisotropy $(A)$, and the eigenvalue relative differences (SERD and DERD). These polarimetric parameters are those resulting from the studies carried out with L-band polarimetric data over bare agriculture fields.

\section{B. Integral Equation Model (IEM)}

To better understand the relationship between the polarimetric parameters and the soil surface characteristics, a backscattering model that is capable of reproducing the radar signal from SAR parameters (incidence angle, polarisation, and radar wavelength) and the soil surface characteristics (dielectric constant and surface roughness) is essential. The Integral Equation Model (IEM: [11], [27]) is one of the physical models that is most widely used because its validity domain covers the range of roughness values that are 
commonly encountered for agricultural surfaces $(k s \leq 3$, where $k$ is the wave number $\cong 1.11 \mathrm{~cm}^{-1}$ for a frequency in the $\mathrm{C}$ band of $5.3 \mathrm{GHz}$ ). The description of surface roughness on bare soils in the IEM is currently based on three parameters [27]: the correlation function, the correlation length, and the standard deviation of heights $(s)$. A number of studies have shown that the backscattering coefficient varies considerably depending on the shape of the correlation function, and the measurements of the correlation length are inaccurate (they are highly dependent on the length and on the number of roughness profiles) [28]-[30].

Over bare soils in agricultural areas, the backscattering coefficient of the surface contribution $\sigma_{p p}^{\circ}$ is expressed for the $\mathrm{HH}$ and VV polarisations ( $\mathrm{pp}=\mathrm{HH}$ or VV) follows:

$$
\begin{aligned}
\sigma_{p p}^{\circ} & =<\left|S_{p p}\right|^{2}>=\frac{k^{2}}{2}\left|f_{p p}\right|^{2} e^{-4 k^{2} r m s^{2} \cos ^{2} \theta} \sum_{n=1}^{+\infty} \frac{\left(4 k^{2} r m s^{2} \cos ^{2} \theta\right)^{n}}{n !} W^{(n)}(2 k \sin \theta, 0) \\
& +\frac{k^{2}}{2} \operatorname{Re}\left(f_{p p}^{*} F_{p p}\right) e^{-3 k^{2} r m s^{2} \cos ^{2} \theta} \sum_{n=1}^{+\infty} \frac{\left(4 k^{2} r m s^{2} \cos ^{2} \theta\right)^{n}}{n !} W^{(n)}(2 k \sin \theta, 0) \\
& +\frac{k^{2}}{8}\left|F_{p p}\right|^{2} e^{-2 k^{2} r m s^{2} \cos ^{2} \theta} \sum_{n=1}^{+\infty} \frac{\left(k^{2} r m s^{2} \cos ^{2} \theta\right)^{n}}{n !} W^{(n)}(2 k \sin \theta, 0)
\end{aligned}
$$

For the cross polarisation, the backscattering coefficient is $\sigma_{H V}^{\circ}$ is as follows:

$$
\begin{aligned}
& \sigma_{h v}^{\circ}=<\left|S_{h v}\right|^{2}>=\frac{k^{2}}{16 \pi} e^{-2 k^{2} r m s^{2} \cos ^{2} \theta} \sum_{n=1}^{+\infty} \sum_{m=1}^{+\infty} \frac{\left(k^{2} r m s^{2} \cos ^{2} \theta\right)^{n+m}}{n ! m !} \\
& \iint\left[\left|F_{h v}(u, v)\right|^{2}+F_{h v}(u, v) F_{h v}^{*}(-u,-v)\right] W^{(n)}(u-k \sin \theta, v) W^{(m)}(u+k \sin \theta, v) d u d v
\end{aligned}
$$

Where:

$$
\begin{aligned}
f_{h h} & =\frac{-2 R_{h}}{\cos \theta} \\
f_{v v} & =\frac{2 R_{v}}{\cos \theta} \\
R_{h} & =\frac{\mu_{r} \cos \theta-\sqrt{\mu_{r} \varepsilon_{r}-\sin ^{2} \theta}}{\mu_{r} \cos \theta+\sqrt{\mu_{r} \varepsilon_{r}-\sin ^{2} \theta}}, \text { being the Fresnel }
\end{aligned}
$$

coefficient at the horizontal polarisation

$$
R_{v}=\frac{\varepsilon_{r} \cos \theta-\sqrt{\mu_{r} \varepsilon_{r}-\sin ^{2} \theta}}{\varepsilon_{r} \cos \theta+\sqrt{\mu_{r} \varepsilon_{r}-\sin ^{2} \theta}} \text {, being the Fresnel }
$$

coefficient at the vertical polarisation

$$
\begin{aligned}
& F_{h h}=2 \frac{\sin ^{2} \theta}{\cos \theta}\left[4 R_{h}-\left(1-\frac{1}{\varepsilon_{r}}\right)\left(1+R_{h}\right)^{2}\right] \\
& F_{v v}=2 \frac{\sin ^{2} \theta}{\cos \theta}\left[\left(1-\frac{\varepsilon_{r} \cos ^{2} \theta}{\mu_{r} \varepsilon_{r}-\sin ^{2} \theta}\right)\left(1-R_{v}\right)^{2}+\left(1-\frac{1}{\varepsilon_{r}}\right)\left(1+R_{v}\right)^{2}\right]
\end{aligned}
$$

$F_{h v}(u, v)=\frac{u v}{k \cos \theta}\left[\frac{8 R^{2}}{\sqrt{k^{2}-u^{2}-v^{2}}}+\frac{-2+6 R^{2}+\frac{(1+R)^{2}}{\varepsilon_{r}}+\varepsilon_{r}(1-R)^{2}}{\sqrt{\varepsilon_{r} k^{2}-u^{2}-v^{2}}}\right]$

$R=\frac{R_{v}-R_{h}}{2}$

$\varepsilon_{r}$ : dielectric constant.

$\mu_{r}$ : relative permittivity

$\theta$ : incidence angle

$\mathrm{s}$ : standard deviation of the surface height

L: correlation length

Re: real part of the complex number

$f_{p p}^{*}$ : conjugate of the complex number $f_{p p}$

$\rho(x, y)$ : surface correlation function. For one-dimensional roughness profiles, $\rho$ is given by:

$\rho(x)=e^{-\left(\frac{x}{L}\right)^{\alpha}}$

The distribution of the surface correlation function is exponential for low surface roughness values $(\alpha=1)$ and Gaussian for high surface roughness values $(\alpha=2)$.

$W^{(n)}$ : Fourier transformation of the nth power of the surface correlation function. It is defined as follows:

$$
W^{(n)}(a, b)=\frac{1}{2 \pi} \iint \rho^{n}(x, y) e^{-i(a x+b y)} d x d y
$$

The empirical model that was developed by [31] was used to link the volumetric water content to the corresponding complex dielectric constant. This model uses the sand and clay composition of the soil.

The IEM satisfies the reflection symmetry assumption, and the coherency matrix can be written as:

$T=\frac{1}{2}\left(\begin{array}{ccc}\left.\left.\left\langle\left|S_{h h}\right|^{2}\right\rangle+2 \operatorname{Re}\left(<S_{h h} S_{v v}^{*}\right\rangle\right)+<\left|S_{w}\right|^{2}\right\rangle & \left.\left.\left\langle\left|S_{h h}\right|^{2}\right\rangle-2 j \operatorname{Im}\left(<S_{h h} S_{v v}^{*}\right\rangle\right)-<\left|S_{v v}\right|^{2}\right\rangle & 0 \\ \left.\left\langle\left|S_{h h}\right|^{2}\right\rangle+2 j \operatorname{Im}\left(<S_{h h} S_{v v}^{*}\right\rangle\right)-\left\langle\left|S_{v w}\right|^{2}\right\rangle & \left.\left.\left\langle\left|S_{h h}\right|^{2}\right\rangle-2 \operatorname{Re}\left(<S_{h h} S_{v v}^{*}\right\rangle\right)+<\left|S_{v v}\right|^{2}\right\rangle & 0 \\ 0 & 0 & \left.4<\left|S_{h v}\right|^{2}\right\rangle\end{array}\right)$

Where $I m$ indicates the imaginary part.

The different polarimetric parameters are next calculated using the polarimetric scattering model IEM. The objective is to analyse the behaviour of these parameters as a function of the soil parameters and to compare this behaviour with the data that were obtained from real SAR data of the RADARSAT-2 sensor.

\section{DATABASE}

A database that was composed of RADARSAT-2 acquisitions and ground measurements over two agricultural study sites in France was used (Fig. 1, Table 1). The first study site is located on the Thau watershed near Montpellier in Southern France $\left(43^{\circ} 26^{\prime} \mathrm{N}\right.$ and $\left.3^{\circ} 40^{\prime} \mathrm{E}\right)$. It is mostly composed of agricultural plots that are intended for growing cereals 
(wheat) and vineyards, natural vegetation (Garrigue=Mediterranean forest), and agricultural wasteland. The second study site is the Orgeval watershed, which is located to the east of Paris $\left(48^{\circ} 51^{\prime} \mathrm{N}\right.$ and $\left.3^{\circ} 07^{\prime} \mathrm{E}\right)$. The Orgeval watershed is mostly composed of agricultural plots that are intended for growing wheat and maize. This site is flat and composed of loamy soils. The measurement campaigns of the soil moisture and surface roughness were conducted simultaneously with the SAR acquisitions on several bare training plots (with low local topography and at least one hectare in size). The soil composition is approximately $52 \%$ silt, $35 \%$ clay, and $12 \%$ sand.

\section{A. Radarsat-2 data}

The C-band SAR images were obtained from the RADARSAT-2 sensor in the polarimetric mode. The radar data are available in fine mode with a spatial resolution of approximately $10 \mathrm{~m}$ and incidence angles of $34-36^{\circ}, 40^{\circ}$, and $45-47^{\circ}$ (Table 1). The PolSARPro v4.2.0 software (http://earth.eo.esa.int/polsarpro/) was used to process the RADARSAT-2 images. The following polarimetric parameters that were considered to be important for the characterization of the soil surface parameters were generated: the angle $\alpha_{1}$, the entropy $(H)$, the anisotropy $(A)$ and the eigenvalue relative differences (SERD and DERD). Next, every generated data layer was geocoded using the MapReady 2.3 software (http://www.asf.alaska.edu/downloads/software_tools) and a Digital Elevation Model at a pixel spacing of 5m (Fig. 2). The geocoding errors were calculated for each RADARSAT-2 image by using an aerial optical image that was acquired by the French National Geographic Institute in 2005 with a spatial resolution of $50 \mathrm{~cm}$. The errors slightly different between one image and another (from $55.9 \mathrm{~m}$ to $62 \mathrm{~m}$ in $\mathrm{X}$ and from $5.6 \mathrm{~m}$ to $10.7 \mathrm{~m}$ in $\mathrm{Y}$ ) were corrected by a simple translation of the images.

Coherency matrices are commonly processed for speckle noise reduction by averaging several neighbouring pixels using a moving window. [32] and [33] have shown that an insufficient number of looks produce an underestimation of entropy and an overestimation of anisotropy and alpha angle (for grass). For a correct retrieval of the physical information, reliable $\mathrm{H}, \mathrm{A}$ and $\bar{\alpha}$ values may be obtained with a minimum of 49 looks. For our RADARSAT-2 data, a 7x7 boxcar filter was applied to the single-look complex data. The average of the polarimetric parameters was then calculated for each training plot.

\section{B. In situ measurements}

Simultaneously to the RADARSAT-2 acquisitions, ground measurements were performed in selected bare training plots ( \pm three hours of the satellite overpass time). Between two and sixteen training plots were visited on each SAR acquisition date (Table 1). Two soil-surface parameters were measured the moisture content (at a $0-5-\mathrm{cm}$ depth) and the surface roughness.

The soil moisture $(m v)$ of each training plot was assumed to be equal to the mean value that was measured from several samples (between 20 and 50) that were collected from that plot in using a calibrated TDR (Time Domain Reflectometry) probe. The soil moistures range from 0.09 to $0.46 \mathrm{~cm}^{3} / \mathrm{cm}^{3}$.

The roughness measurements were made using needle profilometer ( $1 \mathrm{~m}$ long and with $2 \mathrm{~cm}$ sampling intervals). Ten roughness profiles along and across the direction of tillage (five parallel and five perpendicular) were established in each reference field. From these measurements, the two roughness parameters, which are root mean square $(s)$ surface height and correlation length $(L)$, were calculated using the mean of all of the correlation functions. The rms surface heights ranged from $0.5 \mathrm{~cm}$ to $4.0 \mathrm{~cm}$. The correlation length $(L)$ varied from 1.7 $\mathrm{cm}$ in the sown fields to $8.5 \mathrm{~cm}$ in the ploughed fields.

A good characterization of surface roughness is dependant on the roughness profile length, the number of roughness profiles measurements and the horizontal resolution (sampling interval) of profiles [30], [34]-[36]. According to [30], the roughness profiles length should be at least $40 \mathrm{~L}$ and $200 \mathrm{~L}$ (where $L$ is the correlation length) in order to obtain the $s$ and the correlation length with a precision of 10\%. [34]-[35] have demonstrated that shorter profiles result in lower $s$ and correlation length. The underestimation of roughness parameters is more significant for smooth surfaces than for rough roughness. The number of averaged profiles that is required to obtain a standard deviation on $s$ and $L$ less than $10 \%$ is dependent of profile length. [35] demonstrated that less than 10 averaged profiles are required for $1 \mathrm{~m}$ profile to obtain a standard deviation of $s$ lower than $10 \%$, whereas the same accuracy (better than 10\%) for correlation length only becomes feasible for at least 15 averaged profiles. The precision on the correlation length measurements should be about 15 to $20 \%$ for the range of correlation length measured within our bare agricultural fields, with $1 \mathrm{~m}$ profile and 10 average profiles (higher standard deviation for large correlation length). The precision associated with the measurements of $s$ and $L$, were also dependent on the horizontal spacing between height points $(\Delta \mathrm{x})$. According to [35], an increase in horizontal spacing causes a decrease in $s$ and an increase in correlation length, which are more pronounced for surfaces with small correlation length. [30] suggested that the surface should be sampled at a spacing no longer than $0.2 \mathrm{~L}$ and no more than $0.5 \mathrm{~L}$ for the same precision of about $5 \%$ on the correlation length and the s surface height, respectively. For our range of correlation length, the accuracy of roughness parameters with a spacing of $2 \mathrm{~cm}$ should be better than $\pm 10 \%$ for $s$ and between $\pm 10 \%$ and $\pm 20 \%$ for large and small correlation lengths, respectively.

\section{DATA ANALYSIS}

In this section, we will analyze the potential of some of the polarimetric parameters for the soil surface characterization 
(soil moisture « $m v »$ and surface roughness «s»). The data that were calculated from the RADARSAT-2 images and other data that were simulated from IEM are analyzed. The behaviour of polarimetric parameters according to the soil moisture and surface roughness will be studied in using all SAR acquisitions (all data). For the IEM simulations, an exponential correlation function was used with a correlation length of $5 \mathrm{~cm}$, which corresponds to the mean value of in situ correlation length measurements. Indeed, different studies found that the autocorrelation function was well approximated by exponential correlation function for agricultural soils [34], [36]-[39].

To provide a good interpretation of the polarimetric parameters $\alpha_{1}$, entropy, anisotropy, SERD and DERD that were averaged from the RADARSAT-2 images of each training plot, the distribution of the standard deviations that were calculated in the training plots were analyzed (329 data points).

A given polarimetric parameter could be used to discriminate different classes of $m v$ or $k s$ if the distance between the mean values is large compared to the standard deviations [40]. For values of separability $S_{\mathrm{i}, \mathrm{j}}$ between 0.8 and 1.5 , the quality of the separation between classes $i$ and $j$ is average. Values of $S_{\mathrm{i}, \mathrm{j}}$ above 2.0 provide almost complete separation of class pairs. The separability between classes $i$ and $j$ is defined by:

$S_{i, j}=\frac{\left|\mu_{i}-\mu_{j}\right|}{s t d_{i}+s t d_{j}}$

Where $\mu$ and std are mean values and standard deviations of the feature.

Thus, a good separability between two classes of soil moisture or surface roughness requires a difference between their mean values at least equal to twice the standard deviation $\left(S_{\mathrm{i}, \mathrm{j}}=1\right)$.

Fig. 3 shows that the mean of the standard deviations was approximately $3^{\circ}, 0.07,0.09,0.06$, and 0.12 for $\alpha_{1}, \mathrm{H}, \mathrm{A}$, SERD and DERD, respectively. As example, the standard deviation of $\alpha_{1}$ vary between $2^{\circ}$ and $4^{\circ}$ (for $90 \%$ of values) with a mean about $3^{\circ}$. The $\alpha_{1}$ parameter could thus be useful in the mapping of soil moisture or surface roughness if its dynamic is at least of $6^{\circ}$.

Behaviour of alpha angle of the first eigenvector $\left(\alpha_{1}\right)$ according to $\mathrm{mv}$ and $\mathrm{ks}$

The $\alpha_{1}$ parameter indicates the scattering mechanism that is associated with the first eigenvector. $\alpha_{1}$ values that are lower than $45^{\circ}$ correspond to surface scattering. Fig. 4 represents the behaviour of $\alpha_{1}$ according to the soil moisture and $k s$ for three incidence angles, $34^{\circ}, 40^{\circ}$, and $46^{\circ}$. Each value represents the mean parameter of a training site, and it was determined by averaging the values of all of the pixels that belonged to the site.

For an incidence angle of $34^{\circ}, \alpha_{1}$ appeared to decrease with the soil moisture for the $m v$ values that were lower than 10-
$15 \%$ and increase subsequently from $6^{\circ}$ to $12^{\circ}$ for the $m v$ values that were between $15 \%$ and $40 \%$ (Fig. 4a). This behaviour seems to be the same when $k s<1.5$ and $k s>1.5$. Fig. $4 \mathrm{c}$ shows that $\alpha_{1}$ decreases slightly with $k s$ (a decrease of only few degrees for a $k s$ between 1 and 4). Moreover, this decrease is slightly more important for the high $m v$ values $(m v>30 \%)$. For the incidence angles of 40 and $46^{\circ}$, the behaviour of $\alpha_{1}$ was identical to that observed for $\theta=34^{\circ} . \alpha_{1}$ decreased when $m v<10-15 \%$, was constant when $m v$ was between $15 \%$ and $30 \%$, and increased approximately $8^{\circ}$ when $m v$ was between $30 \%$ and $45 \%$ (Fig. 4b). Fig. $4 d$ shows that $\alpha_{1}$ decreased slightly with $k s$ for the incidence angles of $40-46^{\circ}$ and an $m v<30 \%$, and this decrease was only important for the low values of $k s \quad(k s<1)$. Moreover, Fig. 4d shows that the difference between $\alpha_{1}$ of the training plots where $m v<30 \%$ and the training plots where $m v>30 \%$ was higher for the high incidence angles $\left(40-46^{\circ}\right.$ in comparison to $\left.34^{\circ}\right)$. Thus, this parameter could be used to identify the plots that have a high surface soil moisture $(m v>30 \%)$.

The IEM simulations showed a increase of $\alpha_{1}$ with the soil moisture $(m v)$ for the $k s$ that were lower than 1.1 (the threshold value depends slightly on the incidence angle). For the $k s$ values higher than 1.9, $\alpha_{1}$ decreases with $m v$. For the intermediate $k s$ values ( $k s$ between 1.1 and 1.9), $\alpha_{1}$ decreased with $m v$ and then increased (Fig. 5). Moreover, the IEM simulations showed that $\alpha_{1}$ decreased with $k s$ for the $k s$ values that were lower than 1.1-1.9, and then it increases with $k s$ regardless of $m v$. The threshold $k s$ values from which the behaviour of $\alpha_{1}$ changed are highly dependent on the soil moisture (for $\theta=34^{\circ}, k s=1.1$ and 1.9 for $m v=5 \%$ and $40 \%$, respectively) and are slightly dependent on the incidence angle (Figs. 5c and 5d). The simulations confirmed that the response of $\alpha_{1}$ with $k s$ and $m v$ had a dynamic that is slightly lower for a low incidence angle $\left(34^{\circ}\right)$ than for a high incidence angle $\left(46^{\circ}\right)$. However, this dynamic could be insufficient if $m v>15 \%$ because a $10 \%$ differences in the soil moisture resulted in a difference in $\alpha_{1}$ that was lower than $4^{\circ}$ (Figs. 5c, 5d); this difference is of the same order as the standard deviation of $\alpha_{1}$ measurements. A difference of $10 \%$ in $m v$ for $m v<15 \%$ corresponds to an increment in $\alpha_{1}\left(\Delta \alpha_{1}\right)$ that is of $4^{\circ}$ to $7^{\circ}$ for $\theta=46^{\circ}(k s=0.5$ and 3 , respectively). The same difference in $m v$ for $m v>15 \%$ correspond to $\Delta \alpha_{1}$ of less than $4^{\circ}$ for $\theta=46^{\circ}$ and less than $2^{\circ}$ for $\theta=34^{\circ}$.

Ambiguities can appear in the estimation of soil moisture and surface roughness. Indeed, for the same geometric characteristics of the soil surface, the same value of $\alpha_{1}$ could have for some $k s$ two different values of soil moisture (Figs. 5a and 5b). Moreover, Figs. $5 \mathrm{c}$ and $5 \mathrm{~d}$ show that the same value of $\alpha_{1}$ has for a given soil moisture two different values of surface roughness. The part of the curves which is on the left of reflection points of Figs. $5 \mathrm{a}$ and $5 \mathrm{~b}$, or on the right of reflexion points of Figs. 5c and 5d corresponds to the limiting zones of IEM validity. The IEM model validity is limited for rough and dry soils (Figs. 5c and 5d). 
In conclusion, the $\alpha_{1}$ parameter shows good correlation between IEM simulations and RADARSAT-2 data. With respect to the validity domain of the IEM, $\alpha_{1}$ decreases with $k s$ and increases with $m v$.

\section{Behaviour of entropy $(H)$ according to $m v$ and $k s$}

$H$ seemed to decrease slightly with the soil moisture when $m v$ was lower than $15-20 \%$. However, $H$ values of approximately 0.2 increased with $m v$ when the $m v$ values were between $20 \%$ and $45 \%$ (Figs. $6 \mathrm{a}$ and 6b). Moreover, $H$ decreased with $k s$ when the $m v$ values were higher than $30 \%$, and $H$ seemed to be constant when $m v<30 \%$ (Figs. $6 \mathrm{c}$ and $6 \mathrm{~d}$ ). The observed difference in the entropy values for $m v<30 \%$ and $m v>30 \%$ could be useful in the separation of these two soil moisture classes. However, it is difficult to note a clear behaviour of $H$ according to $k s$ except for when $\theta=34^{\circ}$ and $\mathrm{m} v>30 \%$; in this case, $H$ decreased approximately 0.2 for $k s$ between 1 and 2.4 . When $\theta=40^{\circ}$, the entropy seemed to be constant with the $k s$ when $m v<30 \%$.

The IEM simulations showed that $H$ increased slightly with the increase of soil moisture for the $k s$ values that were lower than 1 and decreased for $k s$ values higher than 1.3 (slightly depending on the incidence angle) (Figs. 7a and 7b). Moreover, the IEM showed that $H$ increased strongly with $k s$ for the $k s$ values that were lower than 1-1.3 (the threshold between 1 and 1.3 depends on $m v$ ) and then decreased. The decrease observed on the RADARSAT-2 data between $H$ and $k s$ for $k s$ higher than 1 is weaker than that obtained from the IEM model (less than 0.2 for RADARSAT-2 and about 0.8 for IEM). This could be due to our range of $k s$ which is close to the limit of IEM model validity. Moreover, for the $m v$ corresponding to the ground measurements (generally higher than 10\%), the simulated entropy by the IEM model is almost independent of $m v$ whereas the RADARSAT-2 data shows an increase of $H$ according to $m v$.

\section{Behaviour of anisotropy (A) according to $m v$ and $k s$}

Anisotropy increased with $m v$ for the $m v$ values that were lower than $25 \%$ and $\theta=34^{\circ}$, and it decreased next (Fig. 8a). When $\theta=46^{\circ}, A$ was constant with $m v$ (Fig. 8b). Moreover, the anisotropy decreased with $k s$ when the $k s$ values were lower than 1 by approximately 0.2 for $k s$ between 0.5 and 1 (Fig. $8 d)$. For the $k s$ values that were higher than $1, A$ seemed to be independent of $k s$ (Figs. 8c and 8d). The anisotropy could be used to separate two soil roughness classes: $k s<1$ and $k s>1$.

The IEM simulations showed that $A$ increased slightly with $m v$ (less than 0.1) for $m v$ and $k s$ higher than $10 \%$ and 0.6-0.9 (depending on the incidence angle), respectively (Fig. 9). For our ground measurements where the soil moisture was higher than $10 \%$ and the $k s$ values were higher than 1 (for the majority of our database), the anisotropy increases slightly with $m v$ for both RADARSAT-2 images and IEM model (Figs. 8 and 9).

Concerning the relationship between $A$ and $k s$, the IEM simulations showed that $A$ decreased with $k s$ for the $k s$ values that were lower than $0.6-0.9$; for the $k s$ values that were higher, $A$ increased. When $\theta=40^{\circ}$ and $k s$ was between 0.5 and 1 , the IEM simulations which used the same soil moisture conditions as the ground measurements ( $m v$ was between $19 \%$ and $23 \%$ ) indicated a strong increase of the $A$ parameter by approximately 0.65 . The behaviour of the simulated anisotropy with $k s$ is different from that observed on the RADARSAT-2 images for $k s<1$. It could correspond to the limit of IEM model validity.

Behaviour of single-bounce Eigenvalue Relative Difference (SERD) according to $\mathrm{mv}$ and $\mathrm{ks}$

When $\theta$ was between $34^{\circ}$ and $46^{\circ}$, the SERD parameter was independent of the incidence angle. The SERD was constant when the soil moisture was between $9 \%$ and $30 \%$, and it decreased slightly by approximately 0.1 (Figs. 10a and 10b). The SERD decreased with the $k s$ when $k s<1$, and next, the SERD became constant (Figs. 10c and 10d). This parameter has the same potential as the anisotropy to separate the smooth soils $(k s<1)$ from the rough soils $(k s>1)$. This parameter is slightly less disturbed than the anisotropy (low standard deviations were observed for the mean of SERD) (Fig. 3).

The IEM simulations showed that the SERD decreases with $k s$ for $k s$ values that were lower than 2 (Fig. 11). This same behaviour was also observed on the RADARSAT-2 data but the decrease is much weaker than that on the simulated data (Fig. 10d). For the $k s$ values that were higher than 2, the simulated SERD was almost constant with ks. Moreover, the SERD parameter simulated from the IEM model decreases slightly when the soil moisture increases. This same behaviour was also observed on the RADARSAT-2 data between SERD and $m v$.

In conclusion, this polarimetric parameter presents a weak potential in the discrimination of $k s$ or $m v$ classes.

\section{Behaviour of double-bounce Eigenvalue Relative Difference (DERD) according to $\mathrm{mv}$ and $\mathrm{ks}$}

The DERD parameter was independent of the incidence angle when $\theta$ was between $34^{\circ}$ and $46^{\circ}$. When $\theta=34^{\circ}$, the DERD parameter increased slightly for $m v$ values that were between $9 \%$ and $30 \%$, and it next decreased slightly (Fig. 12a). Moreover, the DERD was constant with the soil moisture when $\theta=46^{\circ}$ (Fig. 12b). The behaviour of the DERD with the $k s$ showed that the DERD decreased with $k s$ for $k s$ values that were lower than 1 and became constant next (Figs. 12c, 12d).

The IEM simulations showed that the DERD decreased with $k s$ for $k s$ values between 0.5 and 1.5 (Fig. 13). This same behaviour was also observed on RADARSAT-2 data but with a weak decrease of the DERD with $k s$. However, the analysis of the standard deviations that were calculated from the RADARSAT-2 data of the mean of the DERD showed that the DERD parameter was more disturbed than the SERD and anisotropy parameters (high standard deviation) (Fig. 3). Moreover, the simulated DERD decreased slightly with $m v$ for $m v$ values between $15 \%$ and $40 \%$. 


\section{CONCLUSION}

The objective of this study was to analyze the potential use of the C-band polarimetric SAR to perform a surface soil characterization over bare agricultural areas. Indeed, few previous studies had investigated this potential and the available studies used especially high-radar wavelengths, such as the L-band. The present study utilized the RADARSAT-2 polarimetric data (C-band) and IEM simulations. The parameters that were chosen in this analysis correspond to the parameters that are frequently used in the literature and are as follows: $\alpha_{1}$, entropy, anisotropy, SERD and DERD. Simultaneously with the RADARSAT-2 acquisitions, field measurements of the soil moisture and surface roughness were performed on several bare soil training fields.

Although the studies in L-band facilitated the collection of polarimetric SAR data that could be used to estimate the soil parameters (characterization of soil parameters), this study shows that the polarimetric parameters in the C-band are not very relevant to the characterisation of the soil surface over bare agricultural area. The high potential that was observed in the L-band is related to the low values of $k s$ and the high dynamics of some of the polarimetric parameters for the low values of $k s(<1)$.

A weak dynamic is often observed in the C-band between the polarimetric parameters and both the soil roughness and moisture content. This weak dynamic does not allow for the direct estimation of the soil parameters, but it could help to improve the inversion standard approaches of the soil parameters by adding a priori information regarding the value ranges for the soil parameters to be estimated (i.e., it could eliminate ambiguities). Indeed, the polarimetric parameter $\alpha_{1}$ could be used to discriminate two soil moisture classes (very wet soils, where $m v>30 \%$ and the remainder, where $m v<30 \%$ ), while the anisotropy $(A)$ could be used to separate the smooth soils $(k s<1)$ from the other soils $(k s>1)$.

The simulations that were obtained from the IEM model showed two divergence problems with the RADARSAT-2 data. First, the dynamics of the polarimetric parameters that were observed in the IEM simulations seemed to be overestimated. In addition, the behavior of the polarimetric parameters (an increase or decrease of the parameters according to $k s$ and $m v$ ) was not always the same one that was observed from the SAR data. These observations suggest that the IEM model in its polarimetric version should be evaluated by other research teams using other databases. If the conclusions of these future studies converge with those that were observed in this study, it will be necessary to improve the robustness of the IEM model.

\section{ACKNOWLEDGMENT}

This work was supported by the FP7 CLIMB project (Climate-induced changes on the hydrology of Mediterranean
Basins) and IRSTEA (National Research Institute of Science and Technology for Environment and Agriculture). The authors wish to thank the CSA (Canadian Space Agency) for kindly providing the RADARSAT-2 data (SOAR-E Project 5032). We also thank Yves Gauthier, Karem Chokmani, and Monique Bernier (INRS-Ete), who very kindly provided their assistance regarding the procurement of the RADARSAT-2 images.

\section{REFERENCES}

[1] E.T. Engman, "Application of microwave remote sensing of soil moisture for water resources and agriculture," Remote Sensing of Environment, 35, pp. 213-226, 1991.

[2] T. J. Jackson, J. Schmugge, and E. T. Engman, "Remote sensing applications to hydrology: Soil moisture," Hydrological Sciences, vol. 41, no.4, pp. 517-530, 1996.

[3] Y. Le Bissonnais, H. Benkhadra, V. Chaplot, D. Fox, D. King, and J. Daroussin, "Crusting, runoff and sheet erosion on silty loamy soils at various scales and upscaling from $\mathrm{m}^{2}$ to small catchments," Soil and Tillage Research, 46, pp. 69-80, 1998.

[4] J. Alvarez-Mozos, J. Casali, M. Gonzalez-Audicana, and N. E. C. Verhoest, "Assessment of the operational applicability of RADARSAT1 data for surface soil moisture estimation," IEEE Transactions on Geoscience and Remote Sensing, vol. 44, pp. 913-924, 2006.

[5] N. Baghdadi, S. Gaultier, and C. King, "Retrieving surface roughness and soil moisture from SAR data using neural network," Canadian Journal of Remote Sensing, 28(5), pp. 701-711, 2002.

[6] N. Baghdadi, N. Holah, and M. Zribi, "Soil moisture estimation using multi-incidence and multi-polarization ASAR SAR data," International Journal of Remote Sensing. 27(10): 1907-1920, 2006.

[7] H. Lievens, N. E. C. Verhoest, E. De Keyser, H. Vernieuwe, P. Matgen, J. Álvarez-Mozos, and B. De Baets, "Effective roughness modelling as a tool for soil moisture retrieval from C- and L-band SAR," Hydrology and Earth System Sciences, 15, 2011, pp. 151-162, doi:10.5194/hess-15-151-2011.

[8] M. S. Moran, C. D. Peters-Lidard, J. M. Watts, and S. McElroy, "Estimating soil moisture at the watershed scale with satellite-based radar and land surface models," Canadian Journal of Remote Sensing, 30, pp. 805-826, 2004

[9] M. Zribi, and M. Dechambre, "A new empirical model to retrieve soil moisture and roughness from C-band radar data," Remote Sensing of Environment, 84, pp. 42-52, 2002.

[10] F. T. Ulaby, R. K. Moore, and A. K. Fung, "Microwave Remote Sensing, Active and Passive, Volume Scattering and Emission TheoryAdvanced Systems and Applications," vol. 3. Artech House: Dedham, MA; 1098 pages, 1986.

[11] A. K. Fung, "Microwave Scattering and Emission Models and their Applications," Artech House, Inc., Boston, London, 573 pages, 1994.

[12] Y. Oh, K. Sarabandi, and F. T. Ulaby, "An empirical model and an inversion technique for radar scattering from bare soil surface," IEEE Transactions on Geoscience and Remote Sensing, 30(2), pp. 370-381, 1992.

[13] Y. Oh, "Quantitative retrieval of soil moisture content and surface roughness from multipolarized radar observations of bare soil surfaces," IEEE Transactions on Geoscience and Remote Sensing, 42(3), pp. 596601, 2004.

[14] H. S. Srivastava, P. Patel, M. L. Manchanda, and S. Adiga, "Use of multiincidence angle RADARSAT-1 SAR data to incorporate the effect of surface roughness in soil moisture estimation," IEEE Transactions on Geoscience and Remote Sensing, 41(7), pp. 1638-1640, 2003.

[15] N. Baghdadi, C. King, A. Bourguignon, and A. Remond, "Potential of ERS and RADARSAT data for surface roughness monitoring over bare agricultural fields: application to catchments in Northern France," International Journal of Remote Sensing, vol. 23, no. 17, pp. 34273442, 2002.

[16] T. Le Toan, "Active microwave signatures of soils and crops: significant results of three years of experiments," In IEEE International 
Geoscience and Remote Sensing, Symposium, Munich, Germany, 1-4 June 1982, pp. 25-32, 1982.

[17] F. T. Ulaby, P. P. Batlivala, and M. C. Dobson, "Microwave Backscatter Dependence on Surface Roughness, Soil Moisture, and Soil Texture: Part I-Bare Soil," IEEE Transactions on Geoscience and Remote Sensing, vol. 16, Issue 4, pp. 286-295, 1978.

[18] S. Allain, "Characterization of bare soils bio- and geo-physical parameters using multi-frequency and multi-resolution SAR data," Ph.D. Dissertation, University of Rennes I, France, 2003, 150 pages.

[19] S. Allain, L. Ferro-Famil, and E. Pottier, "Two novel surface model based inversion algorithms using multi-frequency polSAR data," Proceedings IGARSS 2004, Anchorage, AK, USA, September 20-24, 2004.

[20] S. Allain, L. Ferro-Famil, and E. Pottier, "A polarimetric classification from Polsar data using SERD/DERD parameters," Proceedings EUSAR, Dresden, Germany, May 16-18, 2006.

[21] I. Hajnsek, E. Pottier, and S. Cloude, "Inversion of surface parameters from polarimetric SAR," IEEE Transactions on Geoscience and Remote Sensing, 41(4), pp. 727-744, 2003.

[22] N. Baghdadi, N. Holah, and M. Zribi, "Calibration of the Integral Equation Model for SAR data in C-band and $\mathrm{HH}$ and VV polarizations," International Journal of Remote Sensing, vol. 27, no. 4, pp. 805-816, 2006.

[23] N. Baghdadi, J. Abou Chaaya, and M. Zribi, "Semi-empirical calibration of the Integral quation Model for SAR data in C-band and cross polarization using radar images and field measurements," IEEE Geoscience and Remote Sensing Letters, vol. 8, no.1, pp.14-18, 2011.

[24] Cloude, S. R. and E. Pottier, (1996). A review of target decomposition theorems in radar polarimetry," IEEE Transactions on Geoscience and Remote Sensing, vol. 34, no. 2, pp. 498-518, 1996.

[25] S. V. Nghiem, S. H. Yueh, R. Kwok, and F. K. Li, "Symmetry properties in polarimetric remote sensing," Radio Science, vol. 27, no. 5, pp. 693-711, 1992.

[26] J. J. Van Zyl, “Application of Cloude's target decomposition theorem to polarimetric imaging radar," SPIE, Radar Polarimetry, vol. 1748, pp. 184-212, 1992.

[27] A. K. Fung, Z. Li, and K. S. Chen, "Backscattering from a randomly rough dielectric surface," IEEE Transactions on Geoscience and Remote Sensing, vol. 30, no 2, pp. 356-369, 1992.

[28] E. Altese, O. Bolognani, M. Mancini, and P. A. Troch, "Retrieving soil moisture over bare soil from ERS-1 synthetic aperture radar data : Sensitivity analysis based on a theoretical surface scattering model and field data," Water Resources Research, vol. 32, no. 3, pp. 653-661, 1996.

[29] N. Baghdadi, P. Paillou, M. Davidson, G. Grandjean, and P. Dubois, "Relationship between profile length and roughness parameters for natural surfaces," International Journal of Remote Sensing, vol. 21, no 17, pp. 3375-3381, 2000.

[30] Y. Oh, and Y. Kay, "Condition for precise measurement of soil surface roughness," IEEE Transactions on Geoscience and Remote Sensing, vol. 36, no. 2, pp. 691-695, 1998.

[31] M. Hallikaïnen, F. Ulaby, F. Dobson, M. EL Rayes, and L. Wu, "Microwave dielectric behavior of wet soil. Part I: Empirical models and experimental observations," IEEE Transactions on Geoscience and Remote Sensing, vol. 23, pp. 25-34, 1985.

[32] J. S. Lee, T. L. Ainsworth, J. P. Kelly, and C. Lopez-Martinez, "Evaluation and bias removal of multilook effect on Entropy/Alpha/Anisotropy in polarimetric SAR decomposition," IEEE Transactions on Geoscience and Remote Sensing, 46(10), pp. 30393052, 2008.

[33] C. Lopez-Martinez, and E. Pottier, "Study of the speckle noise effects over the eigen decomposition of polarimetric SAR data," Proceedings of the $2^{\text {nd }}$ international workshop on applications of polarimetry and polarimetric interferometry. Frascati, Italy, 17-21 January 2005 POLinSAR05 (ESRIN, ESA), CDRom.

[34] M. Callens, N. E. C. Verhoest, and M. W. J. Davidson, "Parameterization of tillage-induced single scale soil roughness from 4m profiles," IEEE Transactions on Geoscience and Remote Sensing, vol. 44, no. 4, pp. 878-888, 2006.

[35] H. Lievens, H. Vernieuve, J. Álvarez-Mozos, B. De Baets, N. E. C. Verhoest, "Error in radar-derived soil moisture due to roughness parametrization: an analysis based on systhetical surface profiles," Sensors, 9, 2009, pp. 1067-1093, doi:10.3390/s90201067

[36] N. E. C. Verhoest, H. Lievens, W. Wagner, J. Álvarez-Mozos, S. Moran, and F. Mattia, "On the Soil Roughness Parameterization Problem in Soil Moisture Retrieval of Bare Surfaces from Synthetic Aperture Radar," Sensors, vol. 8, pp. 4213-4248, DOI: 10.3390/s8074213, 2008.

[37] M. W. J. Davidson, T. Le Toan, F. Mattia, G. Satalino, T. Manninen, and M. Borgeaud, "On the characterization of agricultural soil roughness for radar remote sensing studies," IEEE Transactions on Geoscience and Remote Sensing, 38, pp. 630-640, 2000.

[38] M. Zribi, V. Ciarletti, O. Taconet, J. Paillé, P. Boissard, and P. Chapron, "Characterisation of the soil structure and microwave backscattering based on numerical three-dimensional surface representation: analysis with a Brownian model," Remote Sensing of Environment, 72, pp. 159$169,2000$.

[39] A. Ogilvy, and J. M. Foster, "Rough surfaces: Gaussian or exponential statistics," Journal of Physics D-applied Physics, 22, pp. 1243-1251, 1989.

[40] N. Baghdadi, M. Bernier, R. Gauthier, and I. Neeson, "Evaluation of Cband SAR data for wetlands mapping," International Journal of Remote Sensing, vol. 22, no. 1, pp. 71-88, 2001.

Nicolas Baghdadi received the Ph.D. degrees from the University of Toulon, France in 1994. From 1995 to 1997, he was postdoctoral research at INRS ETE - Water Earth Environment Research Centre, Quebec University, Canada. From 1998 to 2008, he was with French geological Survey (BRGM), Orléans, France. Since 2008, he is a Senior Scientist with the National Research Institute of Science and Technology for Environment and Agriculture (IRSTEA), Montpellier, France.

His research activities involve in the areas of microwave remote sensing, image processing, and analysis for satellite and airborne remote sensing data. His main field of interest is the analysis of SAR data and the retrieval of soil parameters (surface roughness and moisture content).

Rémi Cresson received the M.Sc. in signal and image processing from the Grenoble Institute of Technology (INPG), Grenoble, France, 2009. He is currently with IRSTEA for polarimetric radar data processing.

Eric Pottier (M'95, SM'06, F'11) received the MSc and Ph.D. in signal processing and telecommunication from the University of Rennes 1, respectively in 1987 and 1990, and the Habilitation from the University of Nantes in 1998. Since 1999, he has been a Full Professor at the University of Rennes 1, France, where he is currently the Director of the Institute of Electronics and Telecommunications of Rennes (I.E.T.R - CNRS UMR 6164. His current activities of research and education are centered in the topics of analog electronics, microwave theory and radar imaging with emphasis in radar polarimetry. His research covers a wide spectrum of areas from radar image processing (SAR, ISAR), polarimetric scattering modeling, supervised/unsupervised polarimetric segmentation and classification to fundamentals and basic theory of polarimetry.

He has published 9 chapters in books, more than 50 papers in refereed journals and presented more than 340 papers during International Conferences, Symposiums and Workshops. He has presented advances courses and seminars on Radar Polarimetry to a wide range of organizations and events.

He was presented the Best Paper Award at the Third European Conference on Synthetic Aperture Radar (EUSAR2000) and received the 2007 IEEE GRS-S Letters Prize Paper Award.

He has published a book co-authored with Dr. Jong-Sen Lee: Polarimetric Radar Imaging: From basics to applications", CRC Press, Taylor \& Francis editor, 397 pages, January. 2009, ISBN: 978-1-4200-5497-2.

$\mathrm{He}$ is a recipient of the 2007 IEEE GRS-S Education Award "In recognition of his significant educational contributions to Geoscience and Remote Sensing"

He has been elevated to IEEE Fellow (January 2011) with the accompanying citation: "for contributions to polarimetric Synthetic Aperture Radar"

Maelle Aubert received the Master degree in "Geosciences, Environnement, Natural risks" from ULP-EOST, Strasbourg, France (2007). Until 2008, she was Engineer of Institut de Recherche pour le Dévelopement, working on optical objects based classification, Nouméa, New Caledonia. She is currently in $\mathrm{PhD}$ (with IRSTEA) where her research interest is the retrieval of soil 
moisture and surface roughness from SAR imagery. This $\mathrm{PhD}$ is co-financed by CNES and Noveltis, Montpellier, France.

Mehrez Zribi received the engineering degree in signal processing from the Ecole Nationale Supérieure d'Ingénieurs en Constructions Aéronautiques (ENSICA), Toulouse, France, and the Ph.D. degree from the Université Paul Sabatier, Toulouse, France. In 1995, he joined the CETP laboratory (IPSL/CNRS), Vélizy, France. He is employed by CNRS (Centre National de Recherche Scientifique) since 2001. In October 2008, he joined CESBIO laboratory and IRD (Institut de Recherche pour le Développement). His research interests include microwave remote sensing applied to hydrology and microwave modeling and instrumentations.

Andres Jacome is agricultural engineer (Central University of Venezuela) with postgraduate studies in Soil and Water Sciences (Cemagref/AgroParisTech, Montpellier-France). Currently in a Postdoctoral internship at Institut Nationale pour la Recherche Scientifique, Laboratoire Eau Terre Environnement (INRS-ETE, Québec University). Long experience in hydrological simulation for watershed management and soil erosion, land evaluation and environmental impact. Expertise in land survey (soil, land use and land cover, relief) with the help of Geomatics techniques: optical, Radar and LiDAR remote sensing, digital photogrammetric, GIS and DGPS. Academic experience at the Central University in Venezuela (Agronomy Faculty \& Post grade in Soil Science) and at Cemagref/AgroParisTech (Master SILAT, Maison de la Télédétection).

Sihem Benabdallah is an associate professor and researcher at the Centre for Water Research and Technologies in Tunis, Tunisia. Dr. Benabdallah was educated in Tunisia and the United States and holds three degrees in Civil Engineering in addition to her undergraduate training in math and science. Her Ph.D. was earned at Purdue University, and her academic field is hydrologic modeling of watersheds. She is the author of numerous publications on hydrologic and watershed modeling. Prior to her current position, she worked as a consultant on hydrologic studies throughout Africa, as well as studies funded by the European Commission. Dr. Benabdallah was a key organizer of several workshops including a workshop sponsored jointly by the U.S. National Academy of Sciences and its counterpart in Tunisia which focused on improvements in agricultural water management. 


\section{TABLES and FIGURES (only Figure 2 in color)}

TABle 1. PRIMARY CHARACTERISTICS OF THE DATA SET THAT WAS USED IN THIS STUDY: IMAGES CHARACTERISTICS, NUMBER OF TRAINING PLOTS, RANGE OF SOIL MOISTURE, AND SOIL SURFACE ROUGHNESS $(S)$.

\begin{tabular}{|c|c|c|c|c|c|c|c|}
\hline $\begin{array}{c}\text { Date } \\
\text { (yyyy-mm-dd) }\end{array}$ & Site & $\begin{array}{l}\text { Time TU } \\
\text { (hh:mm) }\end{array}$ & $\begin{array}{l}\text { Sensor mode - } \\
\text { Incidence angle }\end{array}$ & Orbit & $\begin{array}{l}\text { Number of } \\
\text { training plots }\end{array}$ & $\begin{array}{l}\text { Soil moisture }(\%) \\
{[\text { min - mean - max }]}\end{array}$ & $\begin{array}{c}\text { Soil } \\
\text { roughness }(\mathbf{c m}) \\
{[\mathbf{m i n}-\mathbf{m a x}]}\end{array}$ \\
\hline 2010-11-18 & Thau & $05: 55$ & 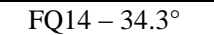 & DES & 11 & {$[9.5-13.3-16.7]$} & {$[0.9-3.3]$} \\
\hline 2010-12-04 & Thau & $17: 48$ & FQ26-45.1 ${ }^{\circ}$ & ASC & 10 & {$[17.0-23.4-33.5]$} & {$[1.2-2.4]$} \\
\hline 2010-12-12 & Thau & 05:55 & FQ14 - 34.3 ${ }^{\circ}$ & DES & 10 & {$[9.0-13.7-17.4]$} & {$[1.0-2.4]$} \\
\hline 2011-01-05 & Thau & $05: 55$ & FQ14-34.3 ${ }^{\circ}$ & DES & 0 & - & - \\
\hline 2011-01-11 & Thau & $17: 39$ & FQ16-36.2 $2^{\circ}$ & ASC & 9 & {$[25.6-28.4-30.2]$} & {$[1.0-2.4]$} \\
\hline 2011-01-21 & Thau & $17: 48$ & FQ26-45.1 $1^{\circ}$ & ASC & 10 & {$[9.9-16.5-27.0]$} & {$[1.0-2.4]$} \\
\hline 2011-01-29 & Thau & $05: 55$ & FQ14-34.3ㅇ & DES & 0 & - & - \\
\hline 2011-02-22 & Thau & $05: 55$ & FQ14-34.3 ${ }^{\circ}$ & DES & 2 & {$[25.3-25.5-25.7]$} & {$[1.3-2.2]$} \\
\hline 2011-03-15 & Thau & $05: 43$ & FQ29-47.4 $4^{\circ}$ & DES & 14 & {$[31.2-38.5-45.7]$} & {$[1.1-4.0]$} \\
\hline 2011-03-18 & Thau & $05: 55$ & FQ14-34.2 $2^{\circ}$ & DES & 16 & {$[18.1-32.0-39.1]$} & {$[1.0-4.0]$} \\
\hline 2010-03-22 & Orgeval & $17: 45$ & FQ20 - $40^{\circ}$ & ASC & 7 & {$[13.8-19.7-23.3]$} & {$[0.5-2.6]$} \\
\hline 2009-04-03 & Orgeval & $17: 41$ & $\mathrm{FQ} 20-40^{\circ}$ & ASC & 8 & {$[14.9-17.1-20.3]$} & {$[1.2-2.6]$} \\
\hline
\end{tabular}

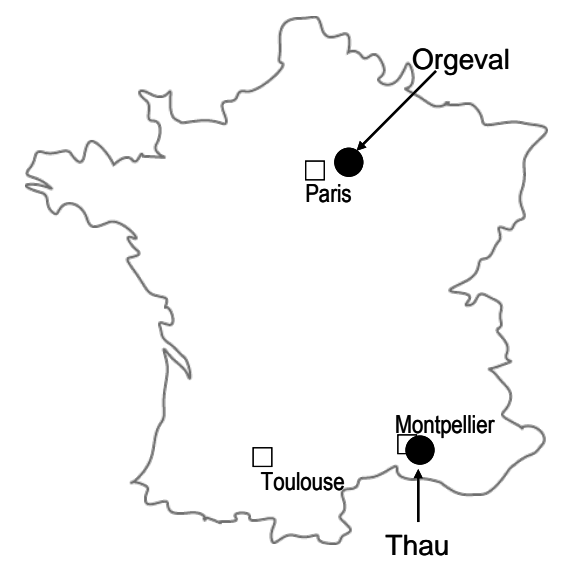

Fig. 1. Location of the Thau and Orgeval basins (France).

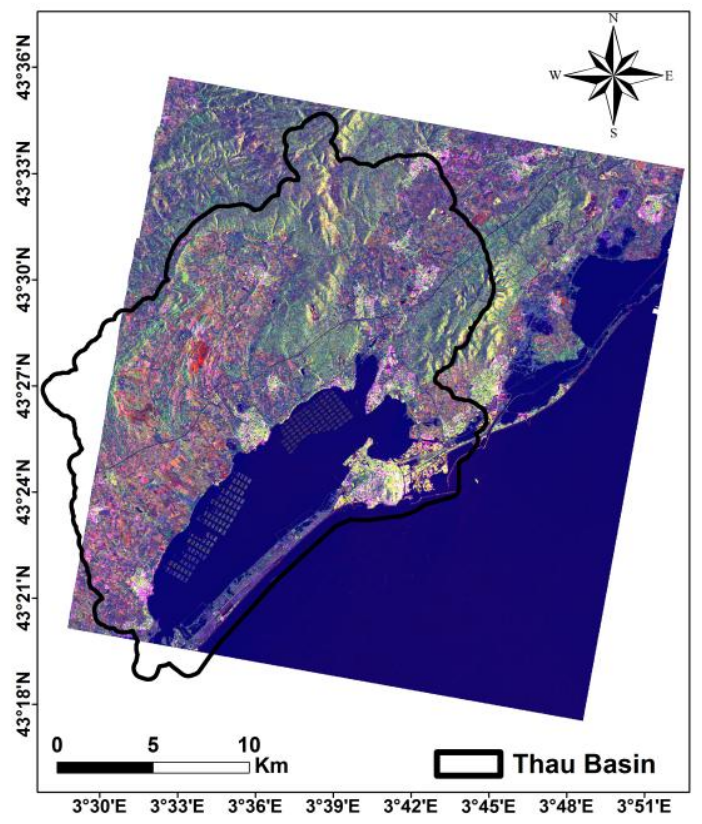

Fig. 2. RADARSAT-2 Quad-Pol image (January 05, 2011) of the study site (Pauli composition: RGB=HH+VV, HV, HH-VV). Size of RADARSAT-2 image: $33.745 \mathrm{~km}$ x $32.336 \mathrm{~km}$; Central coordinates: Lat. $43^{\circ} 26.569^{\prime} \mathrm{N}$ and Long. $3^{\circ} 40.669^{\prime} \mathrm{E}$. The limit of the study site is delineated. 


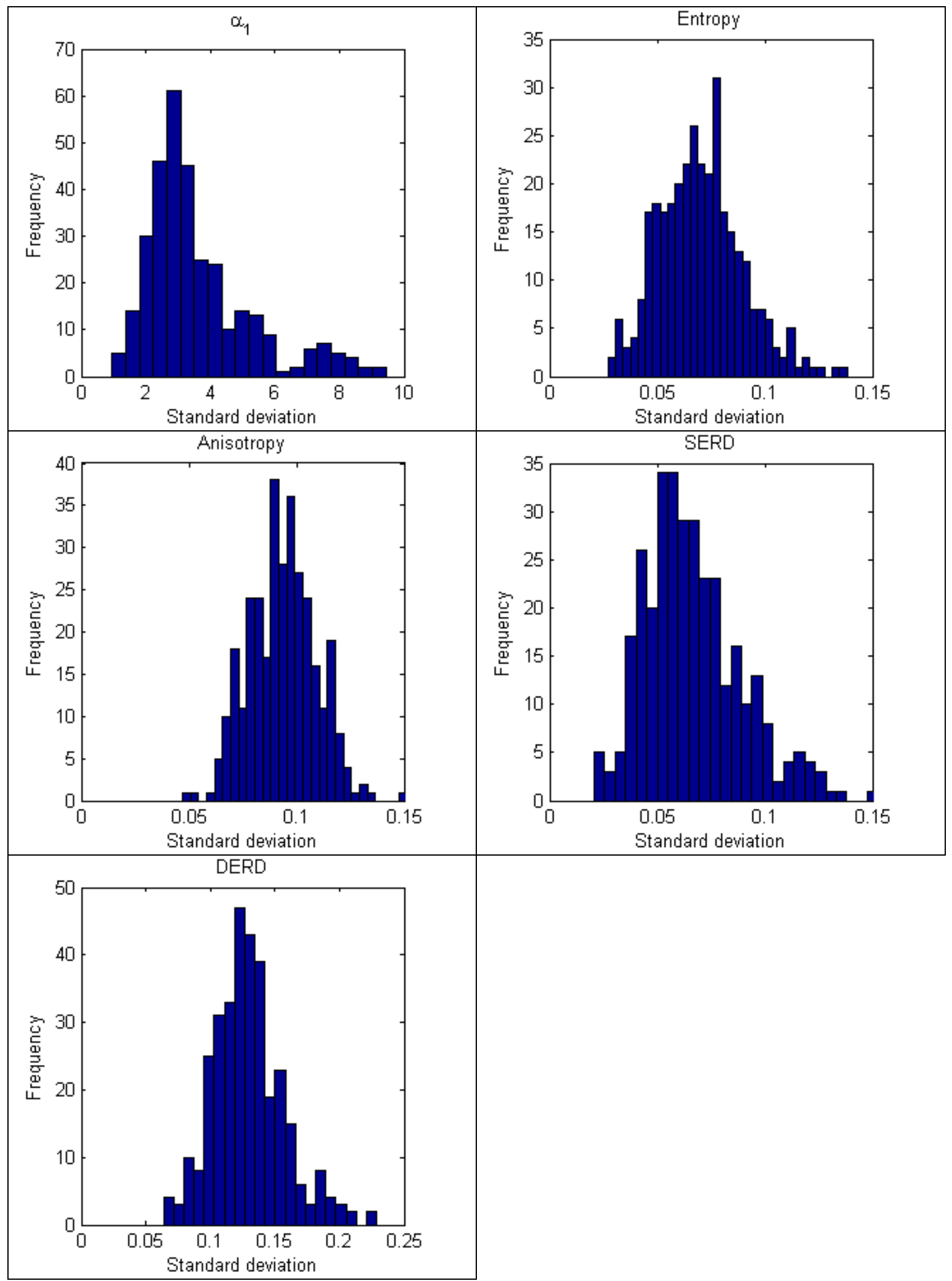

Fig. 3. Histogram of the standard deviations of $\alpha_{1}, H$, A, SERD, and DERD. A database of 329 points was used. Each point corresponds to the standard deviation of a polarimetric parameter that was calculated from a given training plot. 


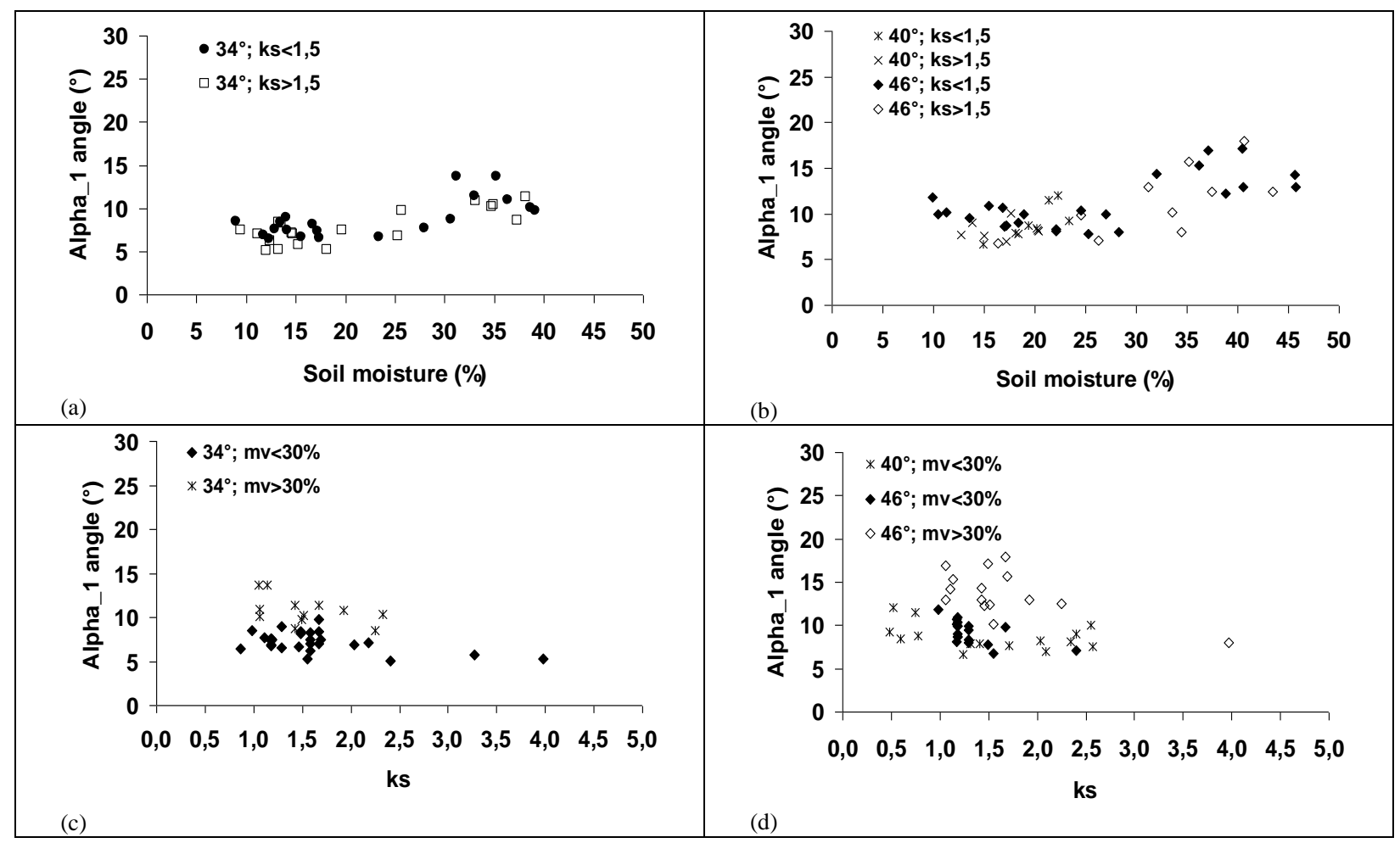

Fig. 4. Behaviour of $\alpha_{1}$ from the RADARSAT-2 data as a function of the soil moisture and ks.

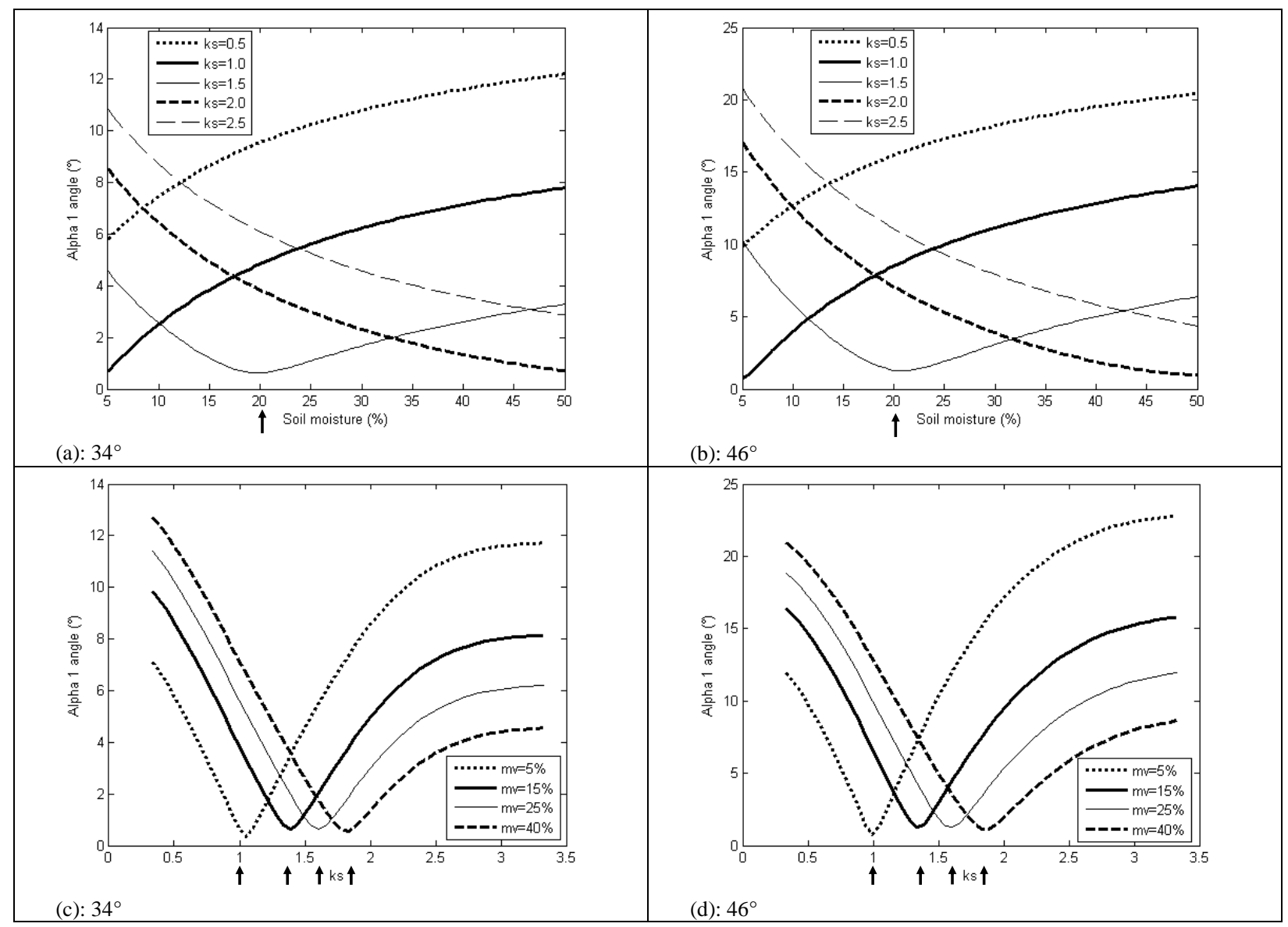

Author-produced version of the article published in IEEE Transactions on Geoscience and Remote Sensing, 2012, 50(10), 3844-3858. The original publication is available at http://ieeexplore.ieee.org 
Fig. 5. Behaviour of $\alpha_{1}$ from the IEM data as a function of the soil moisture and ks. $F=5.3 \mathrm{GHz}$, Exponential autocorrelation function, incidence angles $=34^{\circ}$ and $46^{\circ}$. The change of the polarimetric behaviour is indicated by arrows.

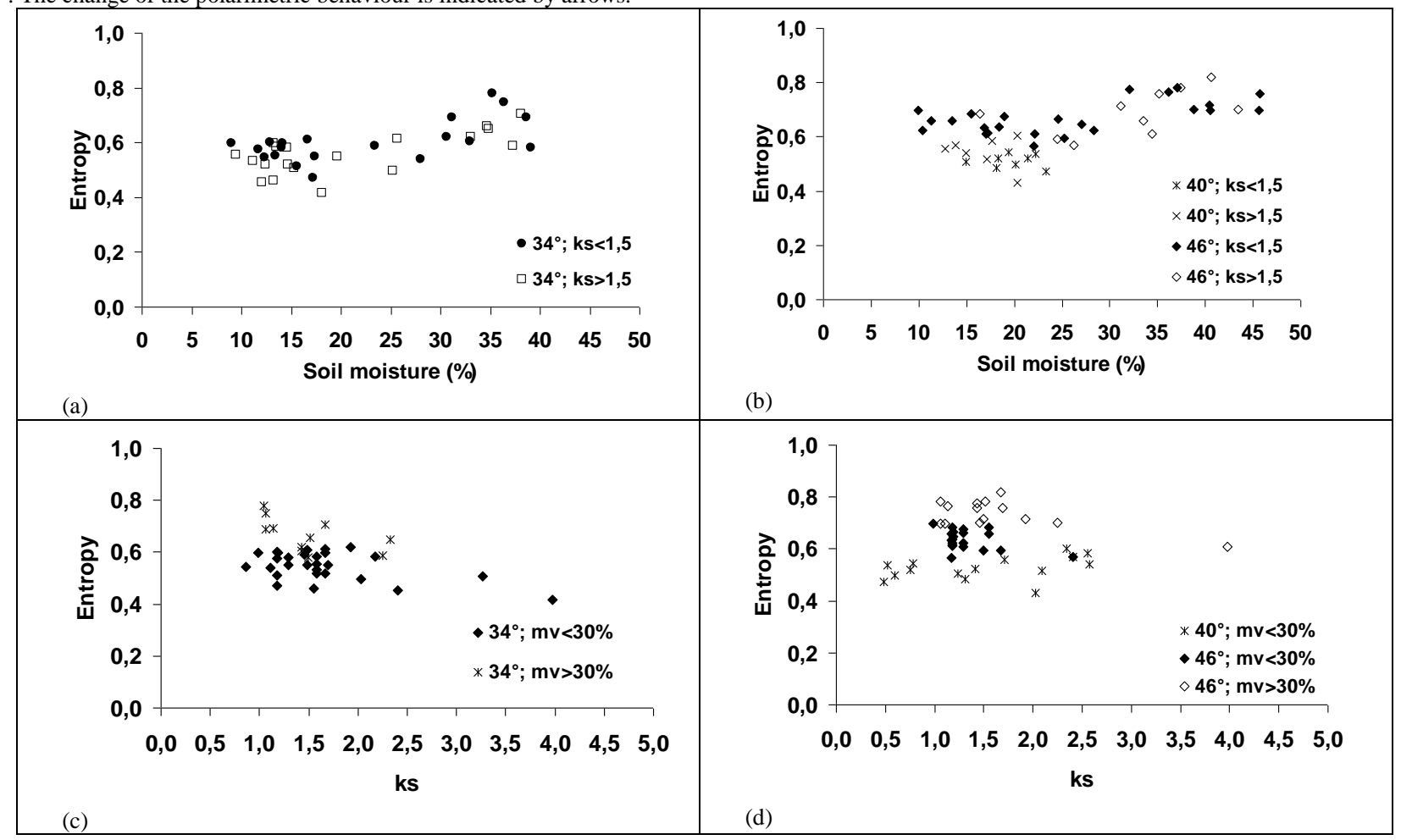

Fig. 6. Behaviour of entropy from the RADARSAT-2 data as a function of the soil moisture and ks.

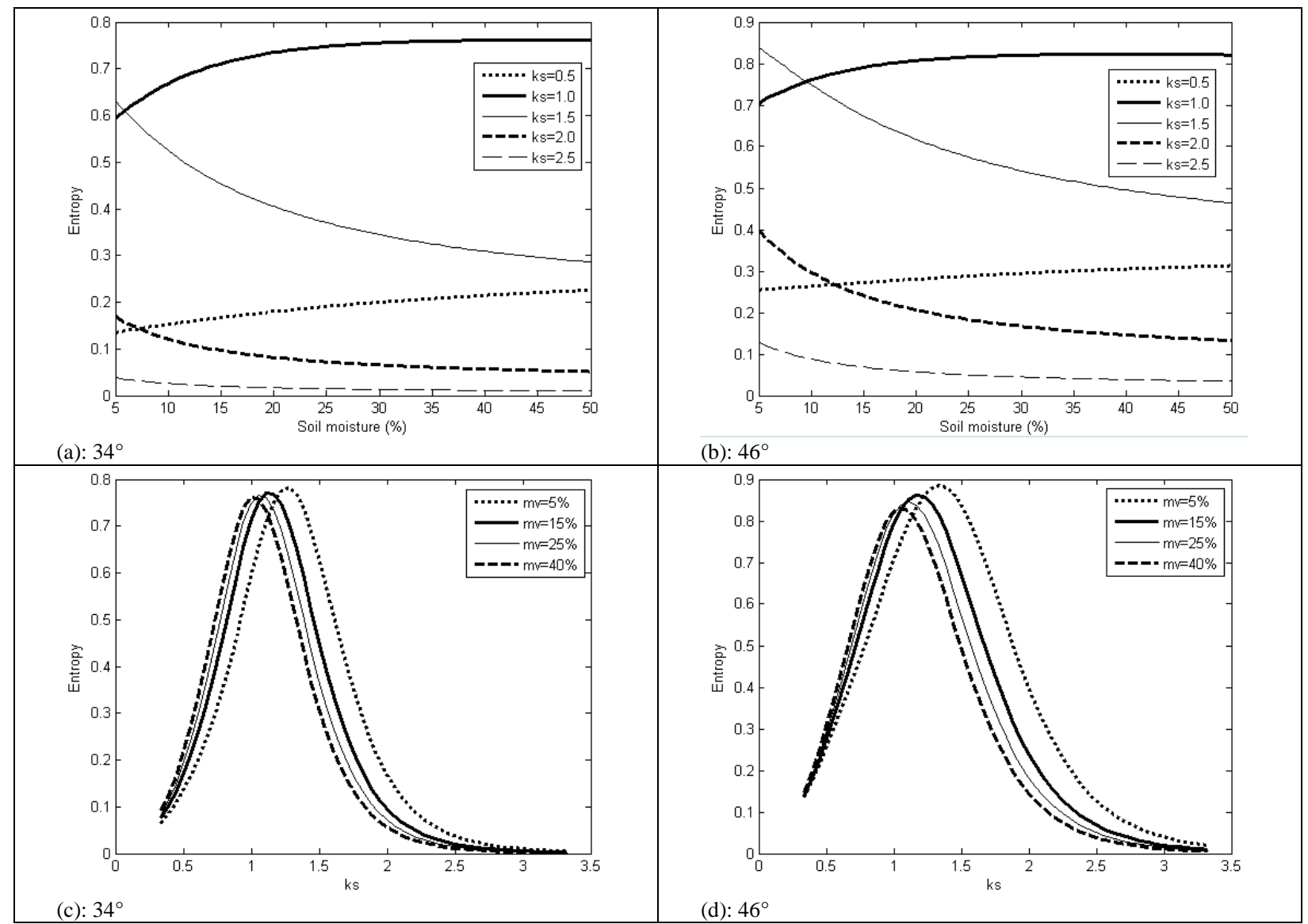

Fig. 7. Behaviour of entropy from the IEM data as a function of the soil moisture and ks. $\mathrm{F}=5.3 \mathrm{GHz}$, Exponential autocorrelation function, incidence angles $=34^{\circ}$ and $46^{\circ}$. 


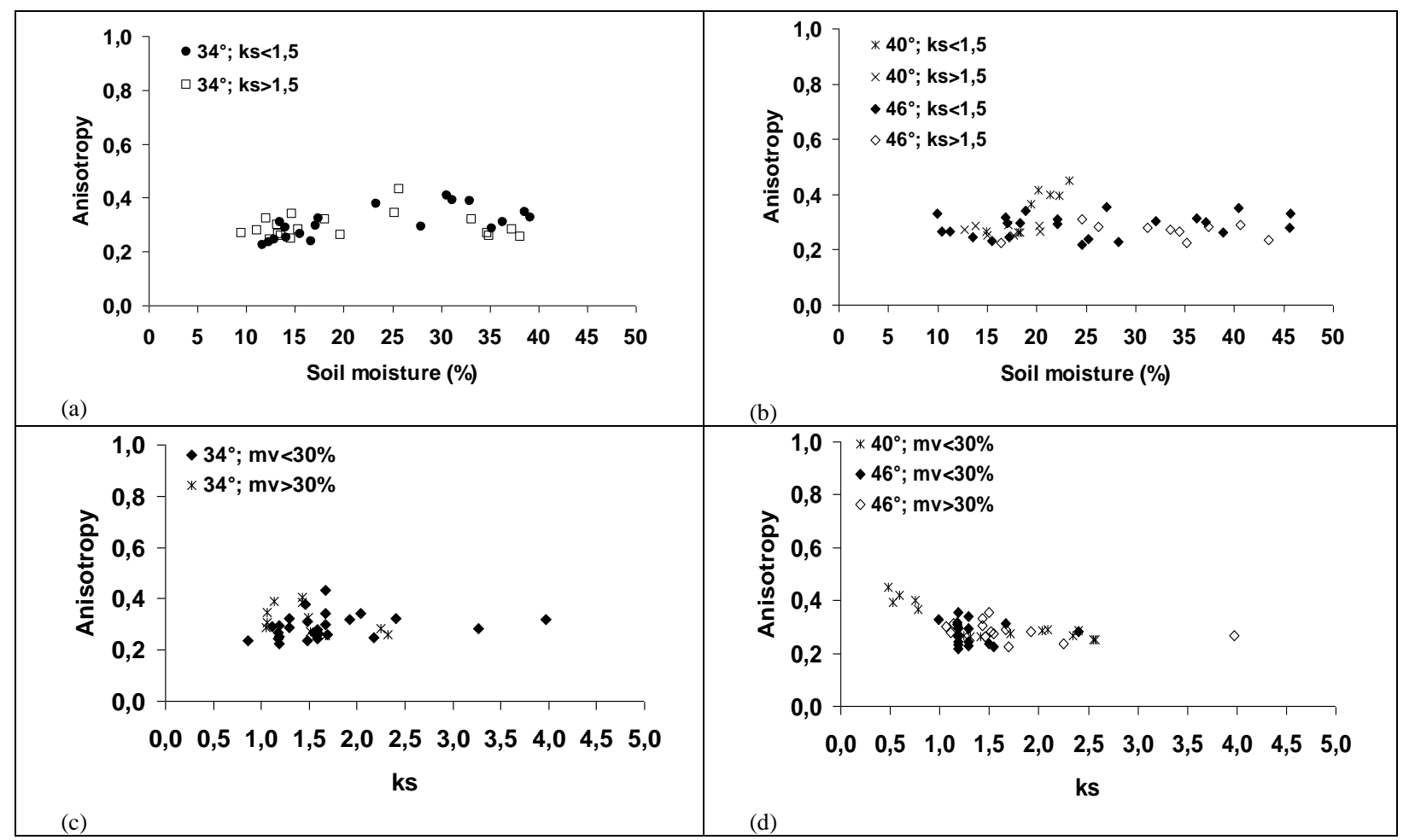

Fig. 8. Behaviour of anisotropy from the RADARSAT-2 data as a function of the soil moisture and ks.

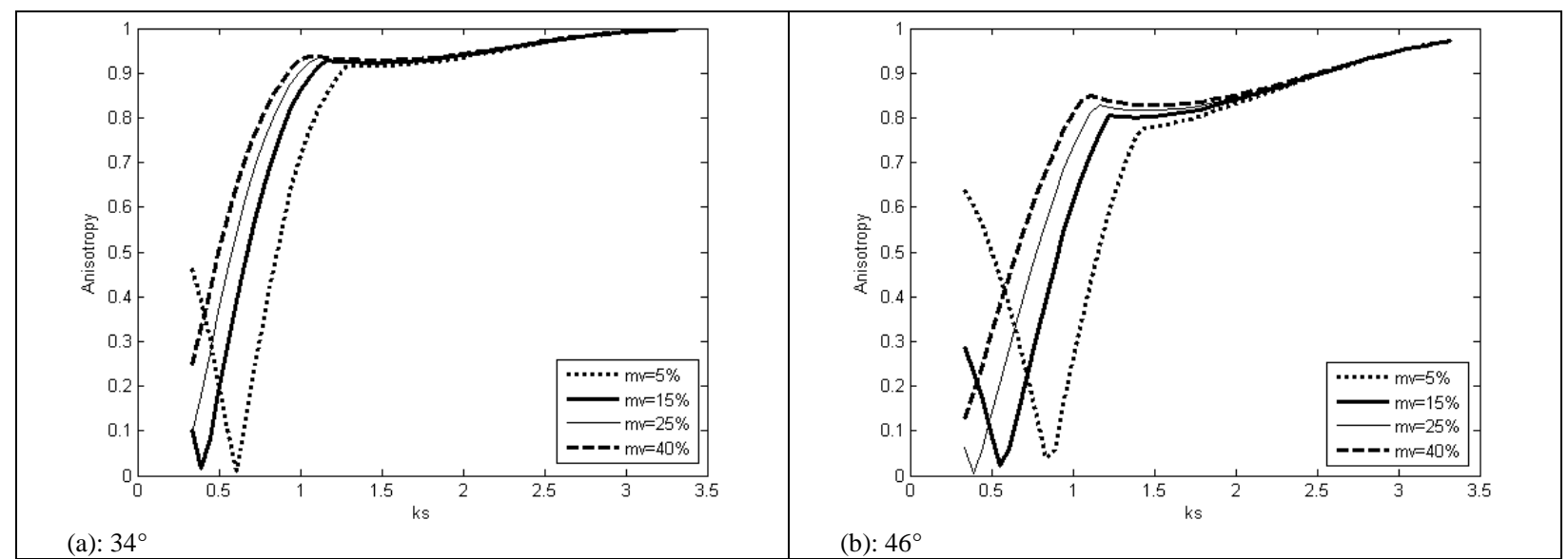

Fig. 9. Behaviour of anisotropy from the IEM data as a function of the soil moisture and ks. F=5.3GHz, Exponential autocorrelation function, incidence angles $=34^{\circ}$ and $46^{\circ}$. 


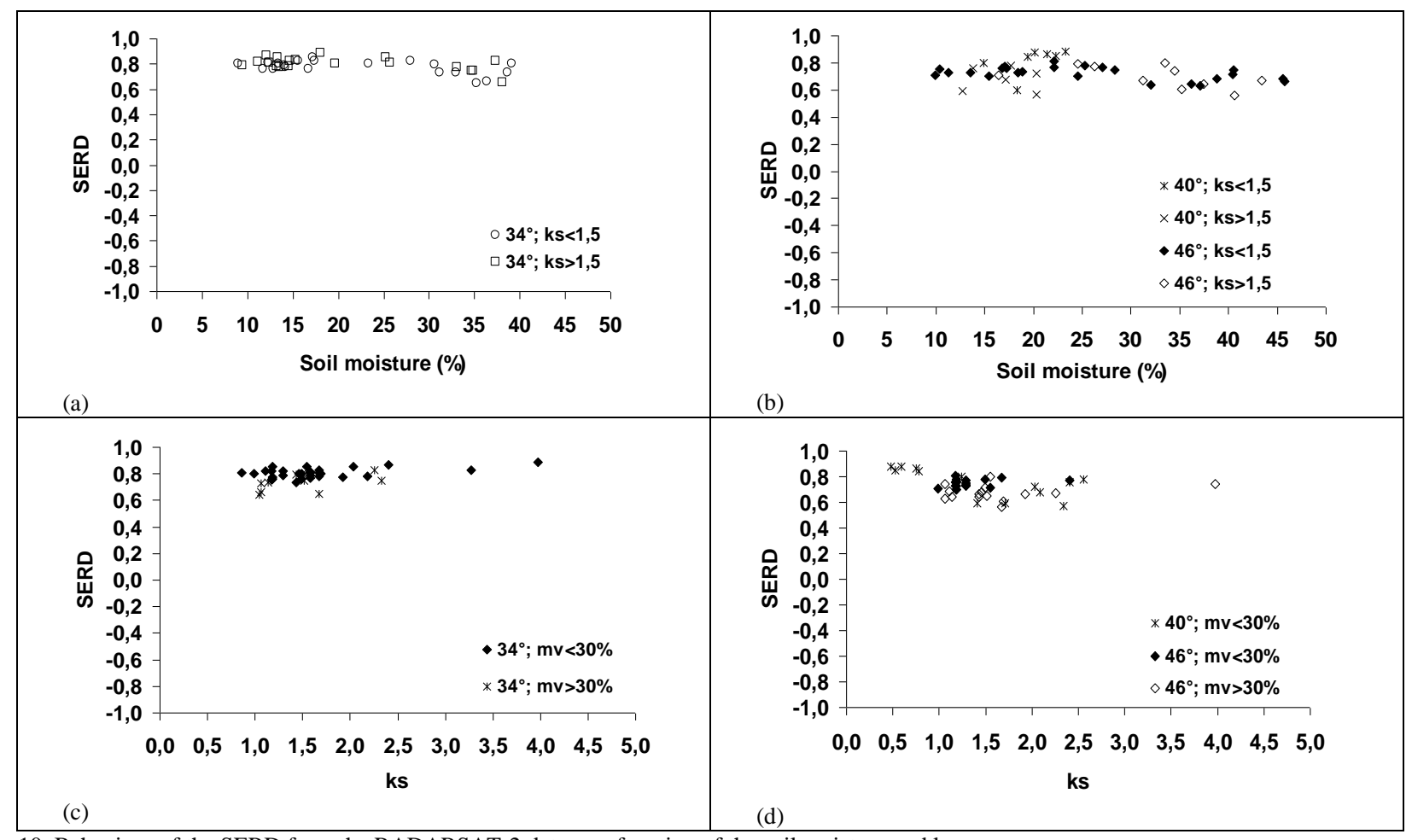

Fig. 10. Behaviour of the SERD from the RADARSAT-2 data as a function of the soil moisture and ks.

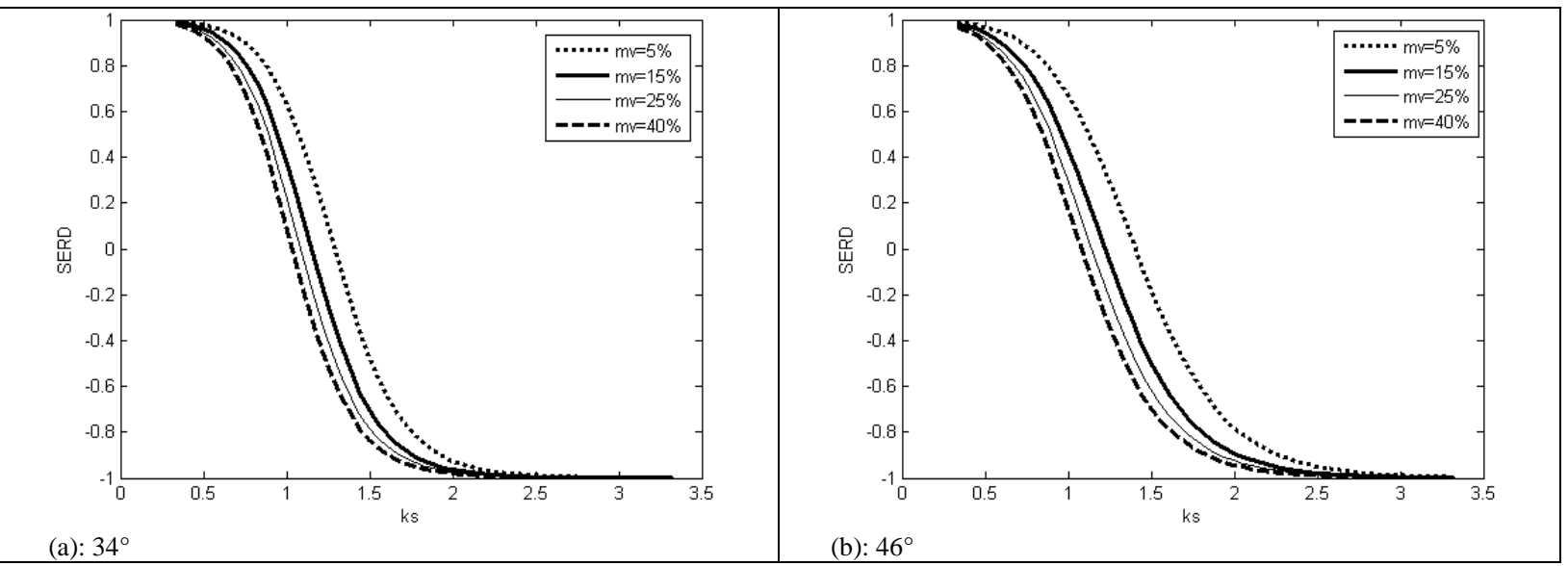

Fig. 11. Behaviour of the SERD from the IEM data as a function of the soil moisture and ks. F=5.3GHz, Exponential autocorrelation function, incidence angles $=34^{\circ}$ and $46^{\circ}$. 


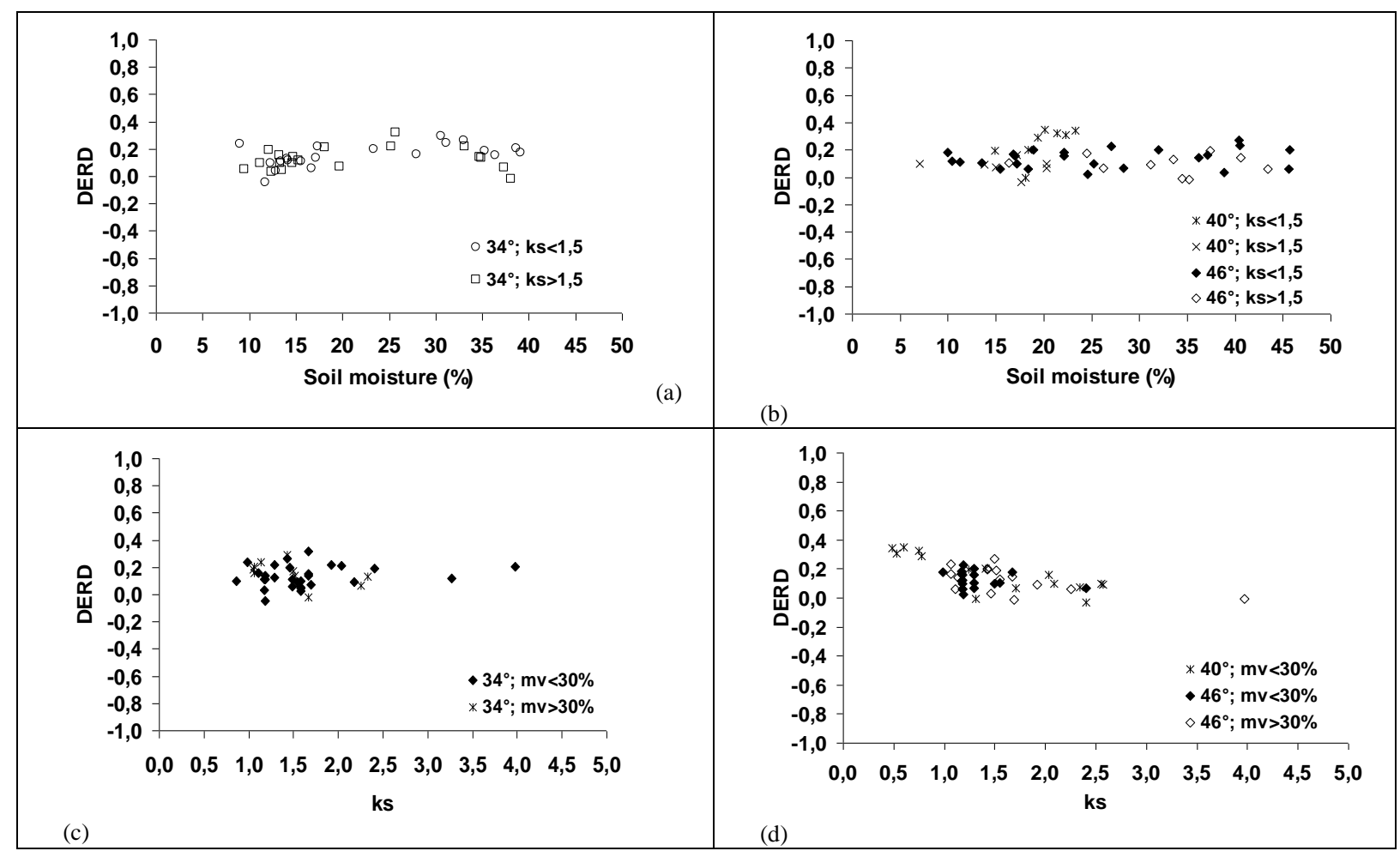

Fig. 12. Behaviour of the DERD from the RADARSAT-2 data as a function of the soil moisture and ks.

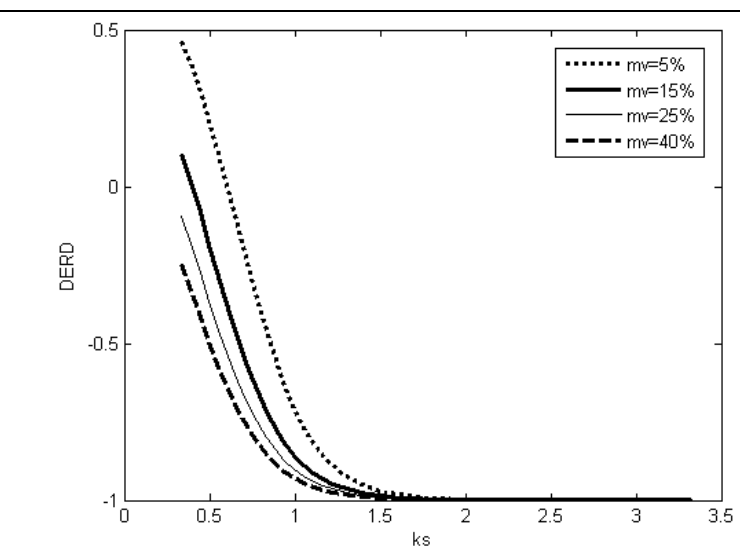

(a): $34^{\circ}$

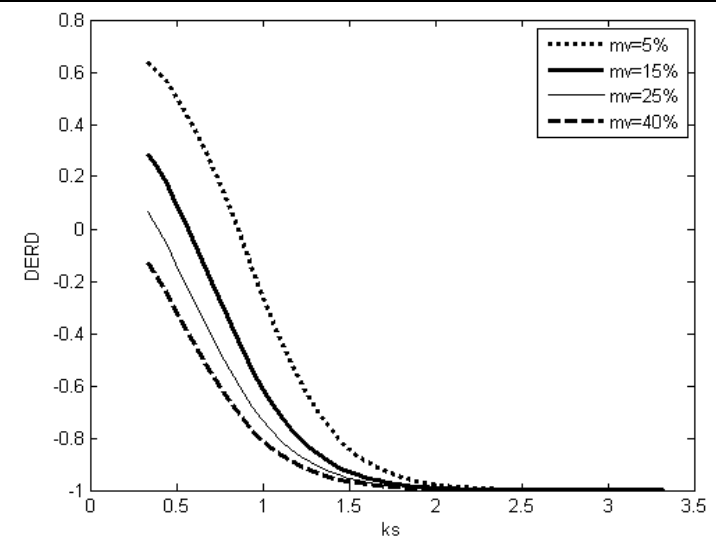

(b): $46^{\circ}$

Fig. 13. Behaviour of the DERD from the IEM data as a function of the soil moisture and ks. $\mathrm{F}=5.3 \mathrm{GHz}$, Exponential autocorrelation function, incidence angles $=34^{\circ}$ and $46^{\circ}$. 


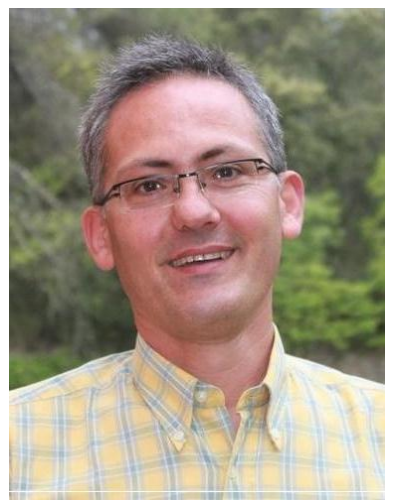

Nicolas Baghdadi

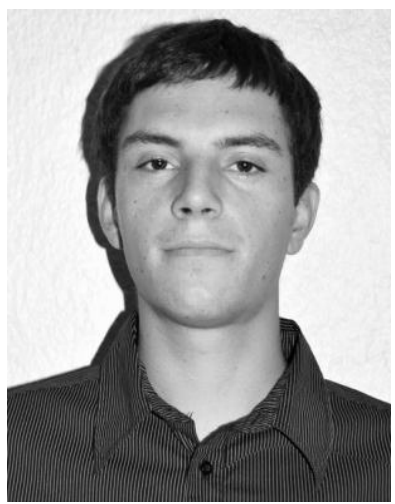

Rémi Cresson

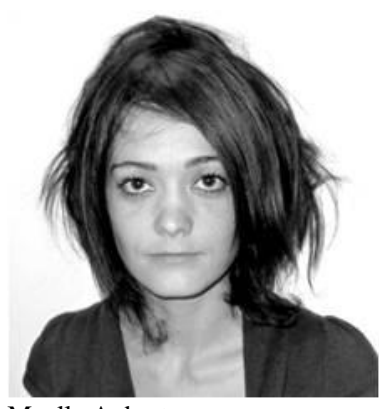

Maelle Aubert

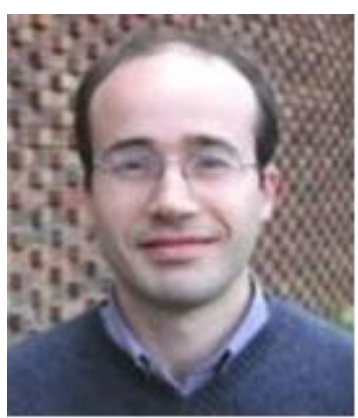

Mehrez Zribi

Author-produced version of the article published in IEEE Transactions on Geoscience and Remote Sensing, 2012, 50(10), $3844-3858$. The original publication is available at http://ieeexplore.ieee.org

DOI : 10.1109/TGRS.2012.2185934 


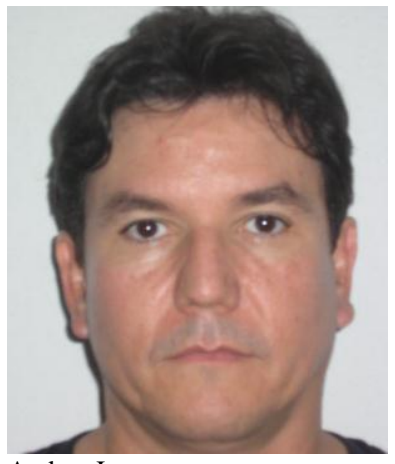

Andres Jacomes

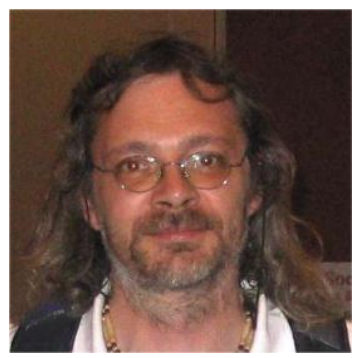

Eric Pottier

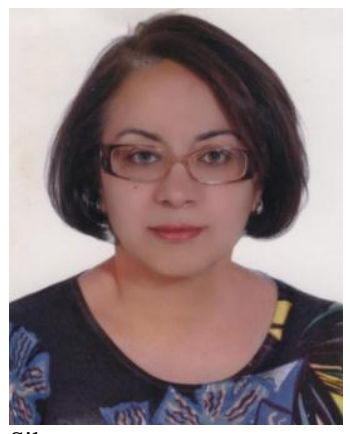

Sihem

Author-produced version of the article published in IEEE Transactions on Geoscience and Remote Sensing, 2012, 50(10), $3844-3858$. The original publication is available at http://ieeexplore.ieee.org DOI : 10.1109/TGRS.2012.2185934 